\title{
Synthesis and Characterization of a Diazirine-based Photolabel of the Non-anesthetic Fropofol
}

E. Railey Whitet, David M. Leacetll, Victoria M. Bedellt, Natarajan V. Bhanuキ, Benjamin A. Garciał, William P. Dailey\$, Roderic G. Eckenhofft*

† University of Pennsylvania, Perelman School of Medicine, Department of Anesthesiology and Critical Care, John Morgan Building 3620 Hamilton Walk, Philadelphia, PA, USA 19104 \# University of Pennsylvania, Perelman School of Medicine, Department of Biochemistry and Biophysics, Smilow Center for Translational Research, 3400 Civic Center Blvd., Philadelphia, Pennsylvania, USA 19104

\$ University of Pennsylvania, Department of Chemistry, 231 S. $34^{\text {th }}$ St., Philadelphia, Pennsylvania, USA 19104

SUPPORTING INFORMATION

\section{Contents}

Page

Figure S1. Proton NMR (500 MHz) of compound 1 3

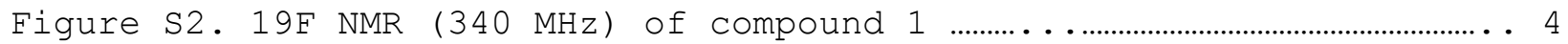

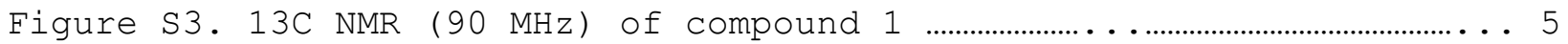

Figure S4. Proton NMR (500 MHz) of compound 3 ........................................................... 6

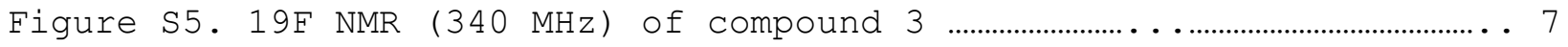

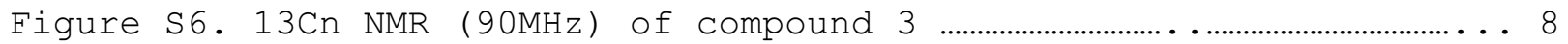


Figure S7. Azi-fropofol extinction coefficient at $273 \mathrm{~nm}$ (..................................................... 9

Figure S8. Determination of 1-AMA Extinction Coefficients 9

Figure S9. Binding affinity of 1-AMA to HSAF ……………………............................10

Figure S10. Fluorescence Spectra of 1-AMA competition assays with AziFo and Fropofol................. 10

Figure S11. HSAF Sequence Coverage ....................................................................... 11

Figure S12. MS/MS spectrum of peptide containing Leu-19 photolabeled site $(10 \mu \mathrm{M}$ AiFo) $\ldots \ldots \ldots . . . . . .12$

Table S1. Ion fragmentation table for peptide containing Leu-19 site (10 $\mu \mathrm{M}$ AiFo) ...................... 13

Figure S13. MS/MS spectrum of peptide containing Leu-24 photolabeled site $(10 \mu \mathrm{M}$ AiFo) ............. 14

Table S2. Ion fragmentation table for peptide containing Leu-24 site (10 $\mu \mathrm{M}$ AiFo) (...................... 15

Figure S14. MS/MS spectrum of peptide containing Gln-82 photolabeled site $(100 \mu \mathrm{M}$ AiFo) $\ldots . . . . . . . . .16$

Table S3. Ion fragmentation table for peptide containing Gln-82 site $(100 \mu \mathrm{M}$ AiFO) (...................... 17

Figure S15. MS/MS spectrum of peptide containing Met-144 photolabeled site $(100 \mu \mathrm{M}$ AiEO) .......... 18

Table S4. Ion fragmentation table for peptide containing Met-144 site $(100 \mu \mathrm{M}$ AiFo) .................... 19

Figure S16. MS/MS spectrum of peptide containing Arg-59 photolabeled site $(100 \mu \mathrm{M}$ AiFo) ........... 20

Table S5. Ion fragmentation table for peptide containing Arg-59 site $(100 \mu \mathrm{M}$ AiFo) (................... 21

Table S6. Ion fragmentation table for peptide containing Arg-59 site (50 $\mu \mathrm{M}$ AiFo) (.................... 22

Figure S17. MS/MS spectrum of peptide containing Asn-17 photolabeled site $(50 \mu \mathrm{M}$ AiFo) (............ 23

Table S7. Ion fragmentation table for peptide containing Asn-17 site (50 $\mu \mathrm{M}$ AiFo) 24 
Figure S18. MS/MS spectrum of peptide containing Leu-24 photolabeled site $(50 \mu \mathrm{M}$ AiFo) ............ 25

Table S6. Ion fragmentation table for peptide containing Leu-24 site (50 $\mu \mathrm{M}$ AiFO) (...................... 27

Figure S19. CASTp analysis of HSAF …………………………………................ 27

Table S7. Lowest Energy Poses from AutoDock Vina Calculations (....................................... 28

Supplemental Methods ............................................................................... 28 28-31 


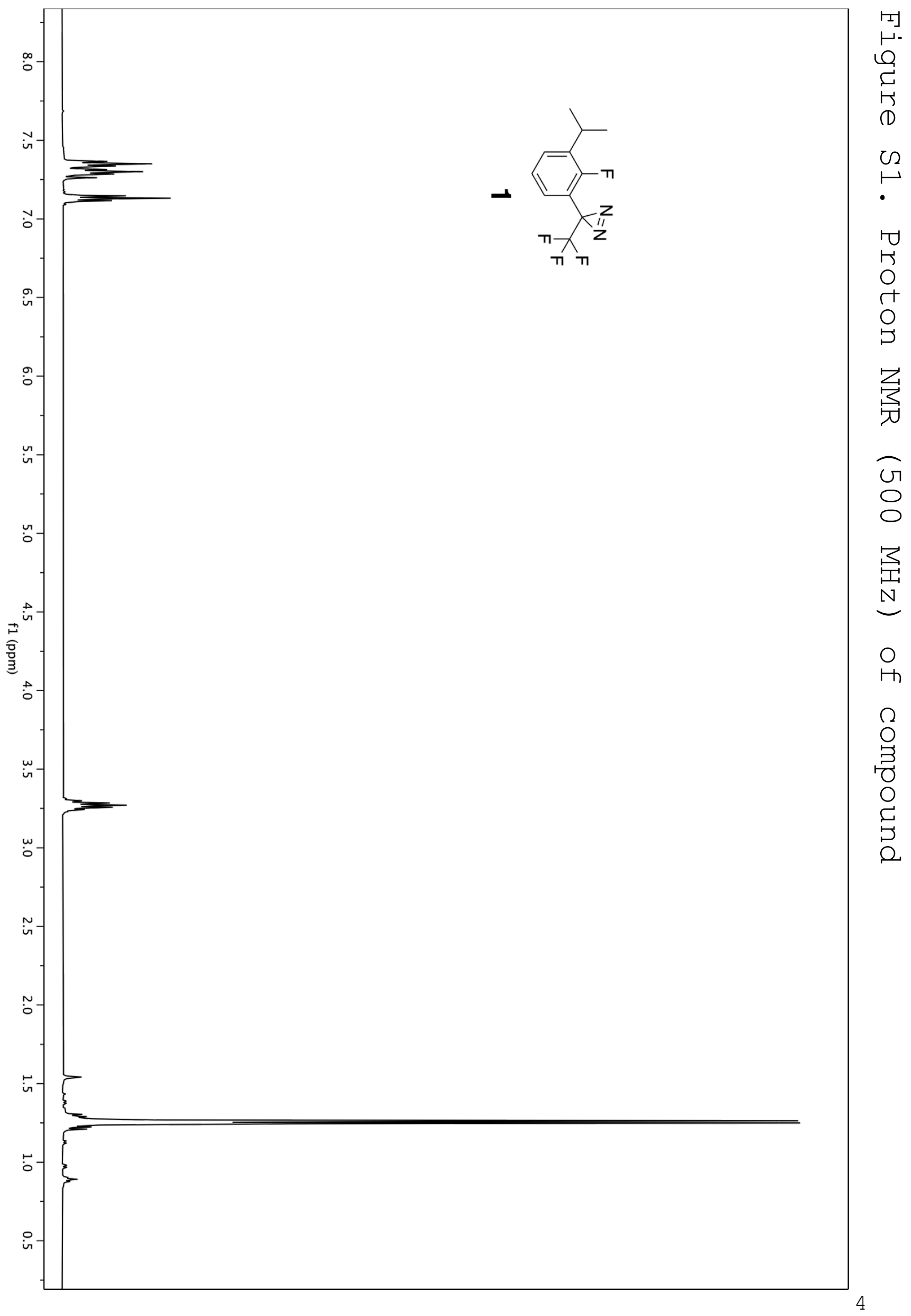




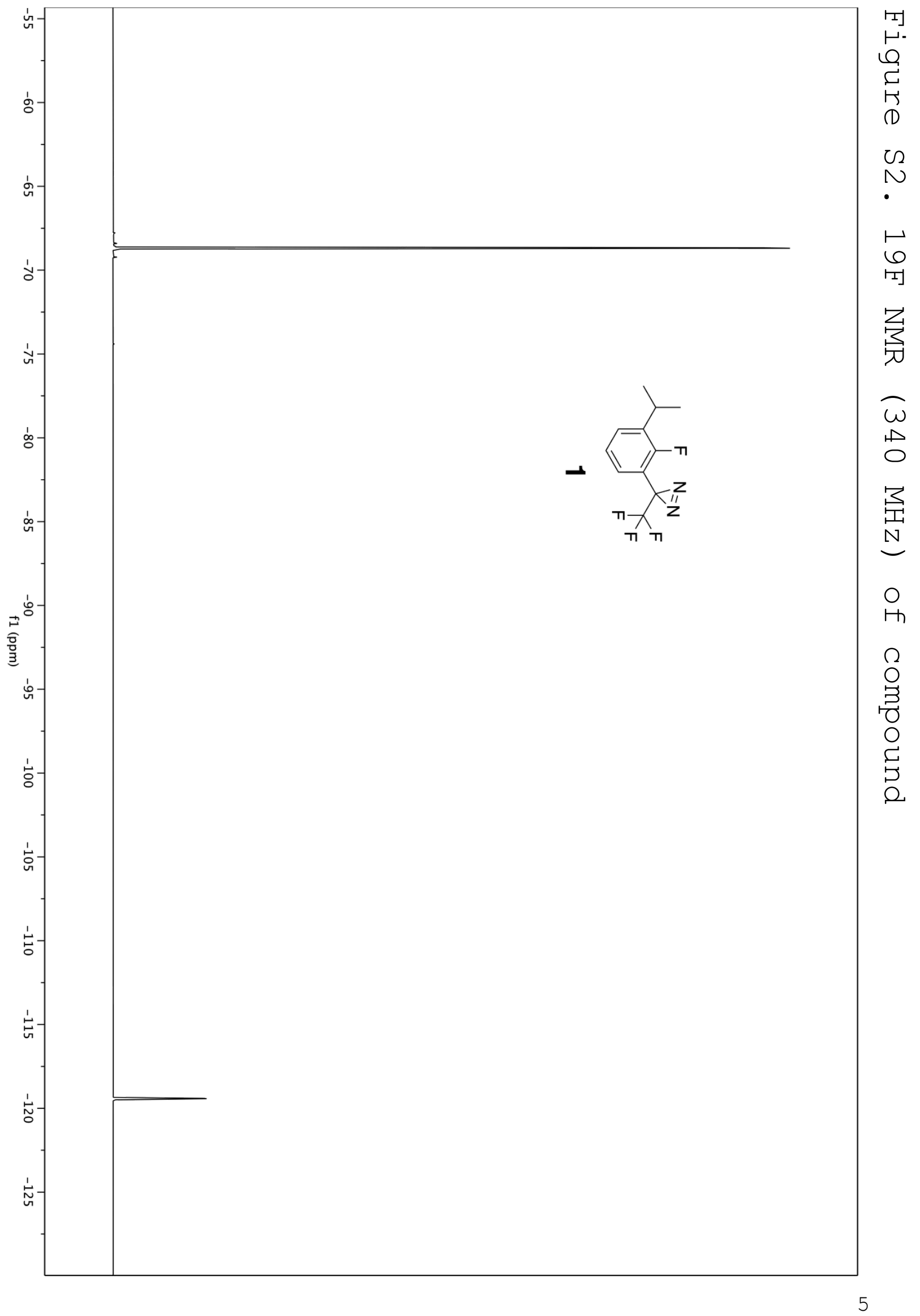




$$
E
$$




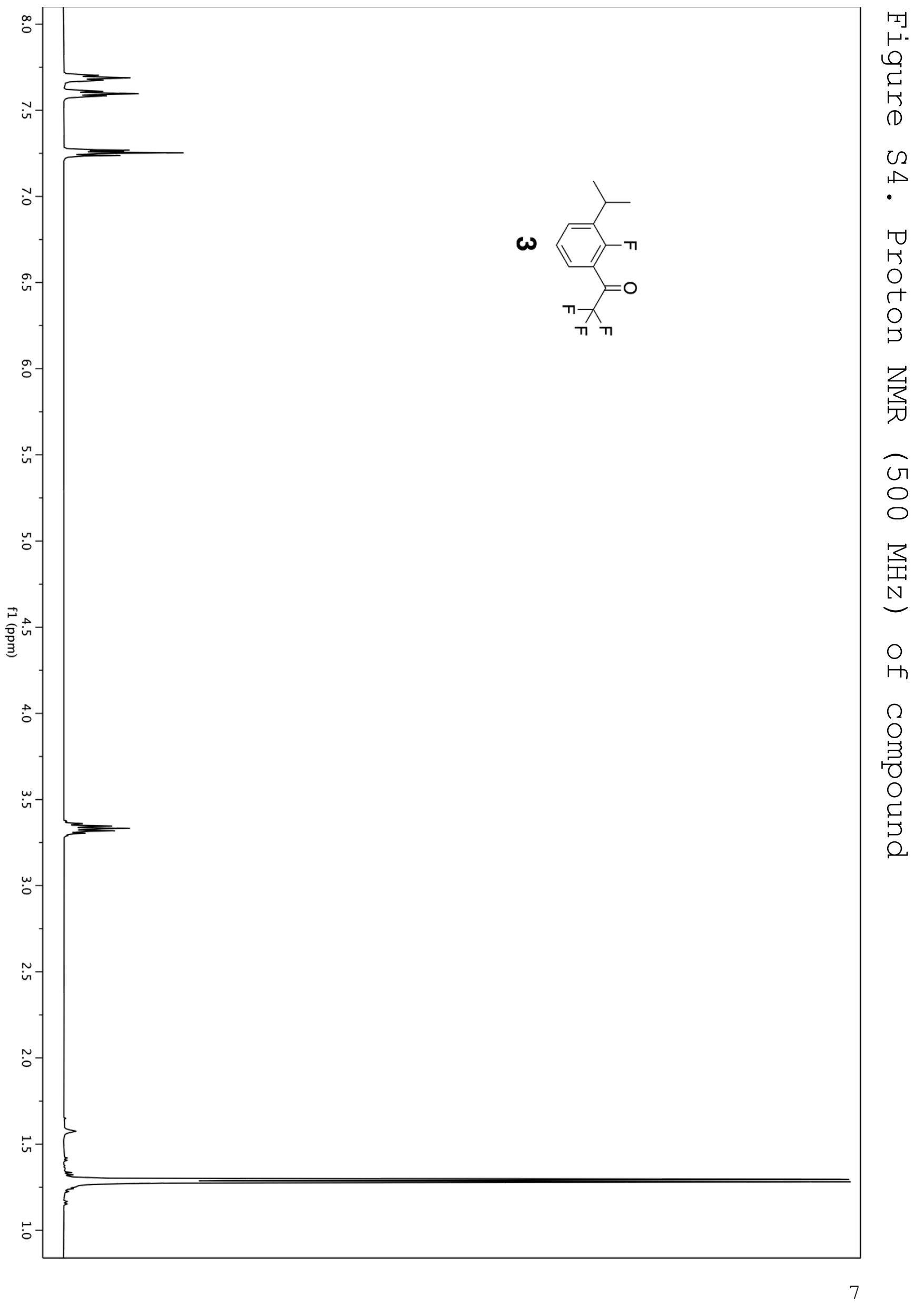




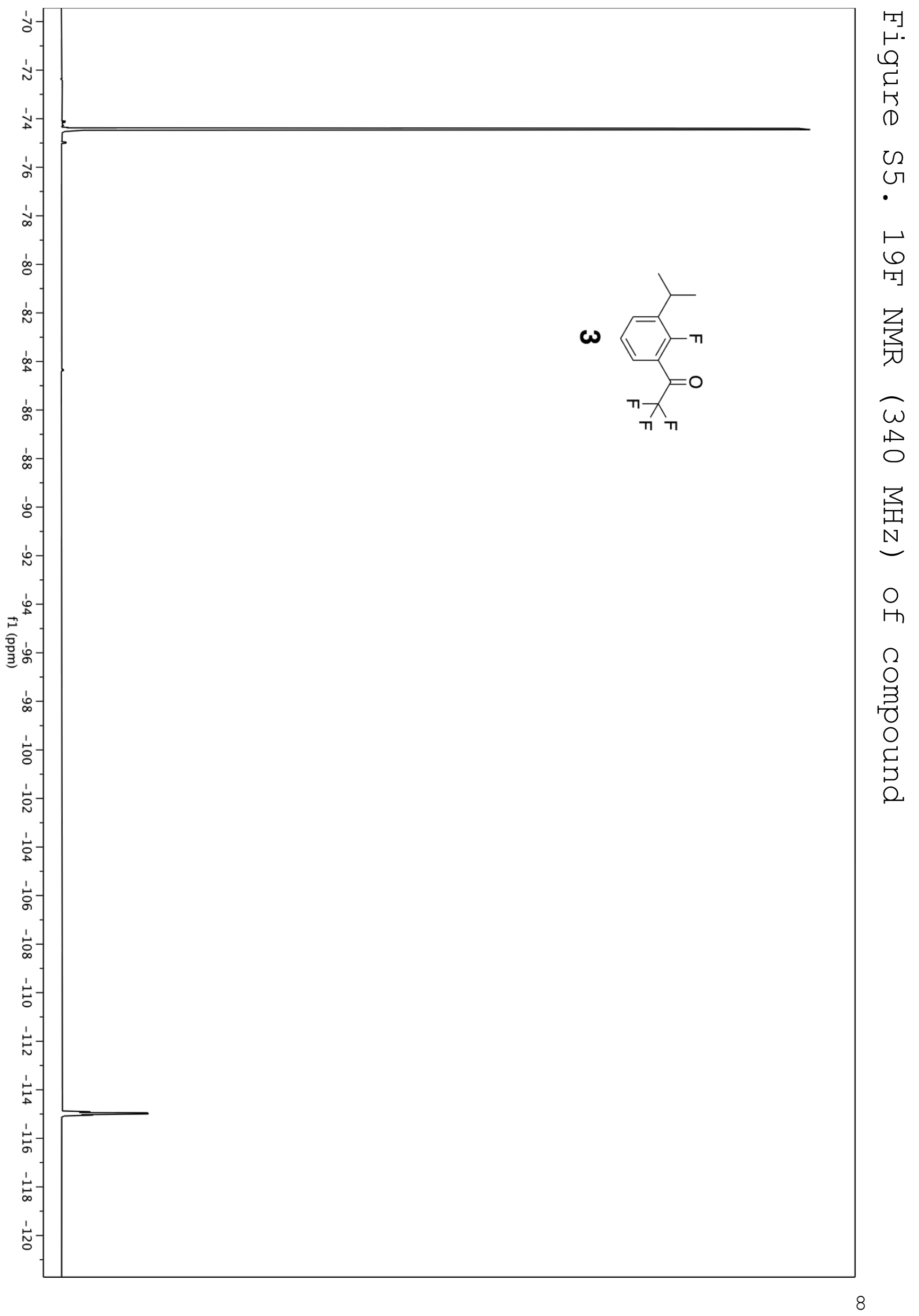




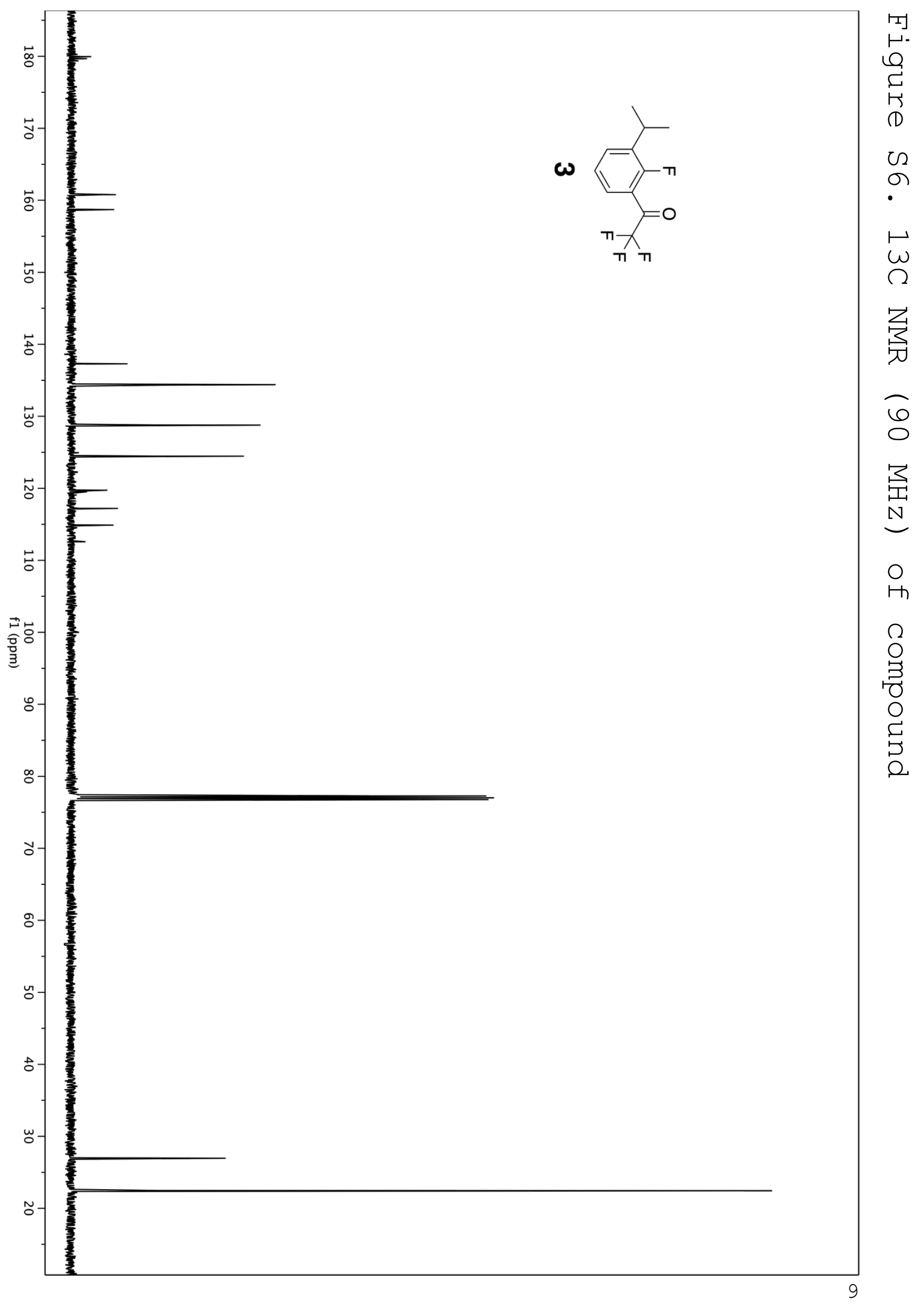



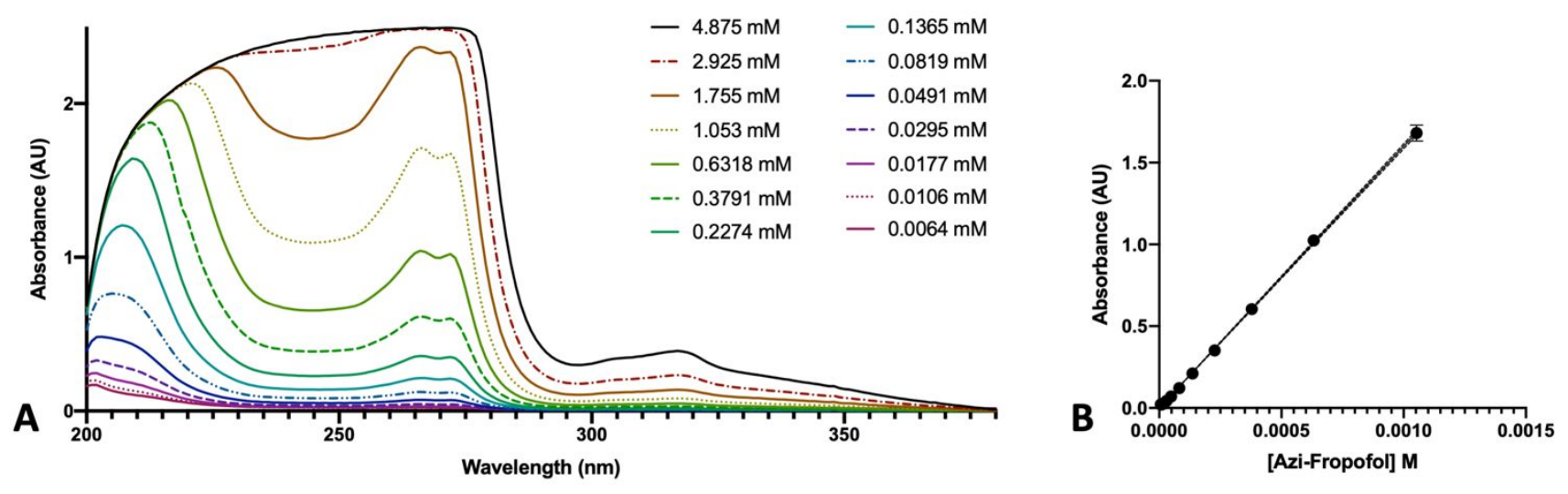

Supplemental Figure S7. Azi-fropofol extinction coefficient at 273 nm. A) UV-Vis spectra of methanolic solutions of AziFo at concentrations indicated. Local maxima were determined to be at 316 , 267, and 273. B) Plot of absorbances at $273 \mathrm{~nm}$. Extinction coefficient determined by linear relationship of Beer's law. R2 value of linear regression was 0.9998. Linear regression was force fit through zero. 95\% Confidence bands are shown on plot. Error bars show standard deviation. Linear concentration range was $1.05 \mathrm{mM}$ to $6.4 \mu \mathrm{M}$.

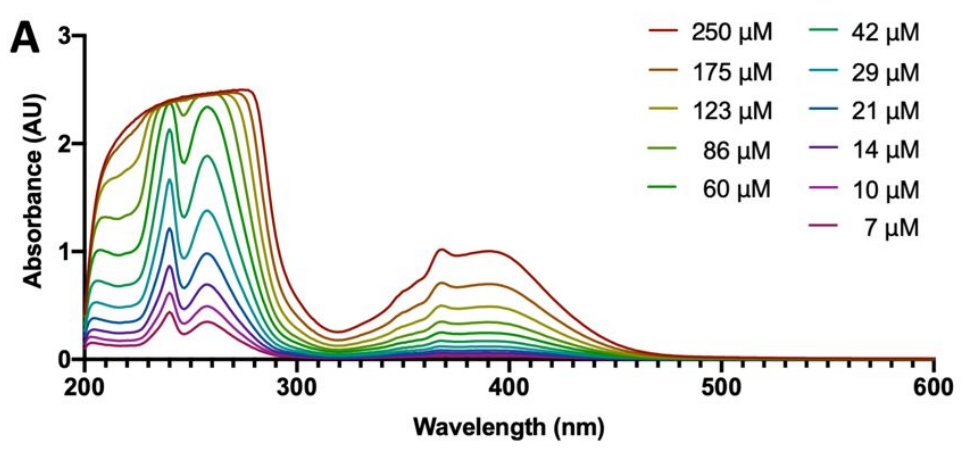

$\begin{array}{lcr}\text { Supplemental } & \text { Figure } & \text { S8. } \\ \text { Determination } & \text { of } & \text { 1-AMA }\end{array}$ Extinction Coefficients. A) UV-Vis spectra of methanolic 1-AMA solutions of known concentration. $B$ and $C$ ) Linear plot of 1-AMA absorbance at $368 \mathrm{~nm}$ and 240 nm respectively. Linear regressions were force fit through zero. 95\% confidence bands are shown on both graphs. Extinction coefficient at $368 \mathrm{~nm}\left(\Sigma_{368}\right)$ was found to be $4070 \mathrm{M}^{-1} \mathrm{~cm}^{-1}$. Extinction coefficient at (11-AMA] (M)

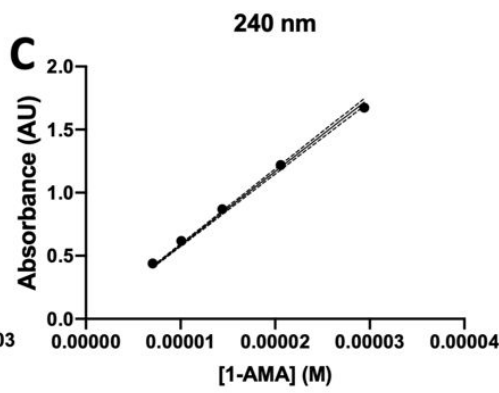
$240 \mathrm{~nm}\left(\Sigma_{\supset \Delta n}\right)$ was found to be 

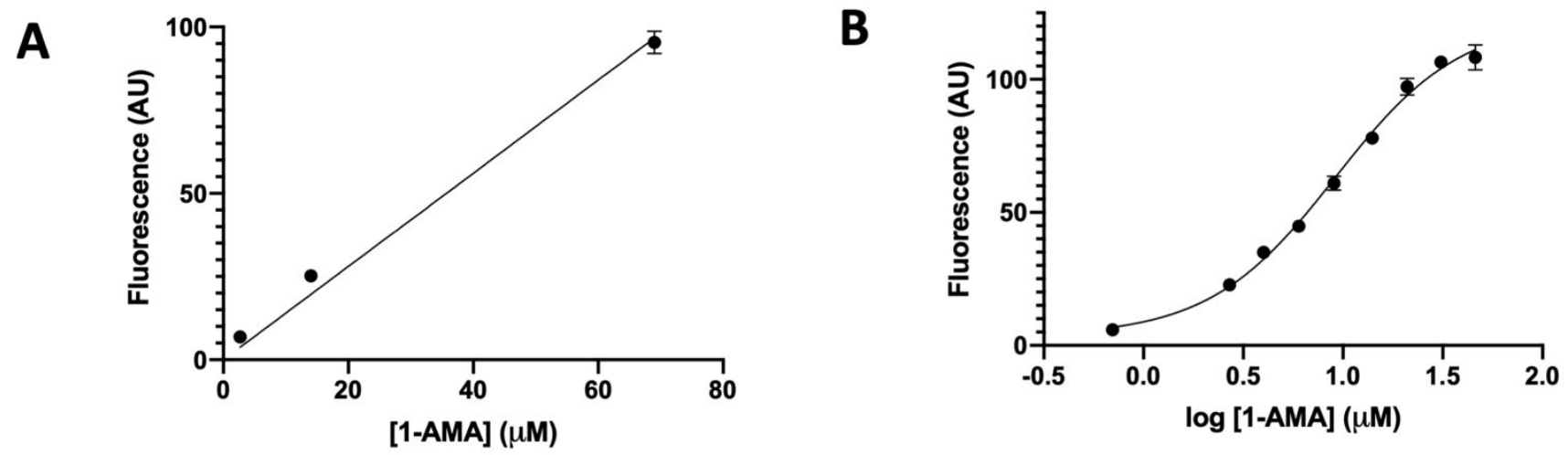

Supplemental Figure S9. Binding affinity of 1-AMA to HSAF. A) Fluorescence of 1-AMA alone. Slope of linear regression was 1.4 (95\% CI 1.3-1.5), error bars show standard deviation. These values were used to account of the fluorescence of unbound 1-AMA. B) Plot used to determine binding affinity of HSAF and 1-AMA. HSAF concentration remained constant at $15 \mu \mathrm{M}$ (dimer) while 1-AMA was added at the indicated concentrations. The calculated fluorescence signal of 1AMA lone was subtracted from each data point.

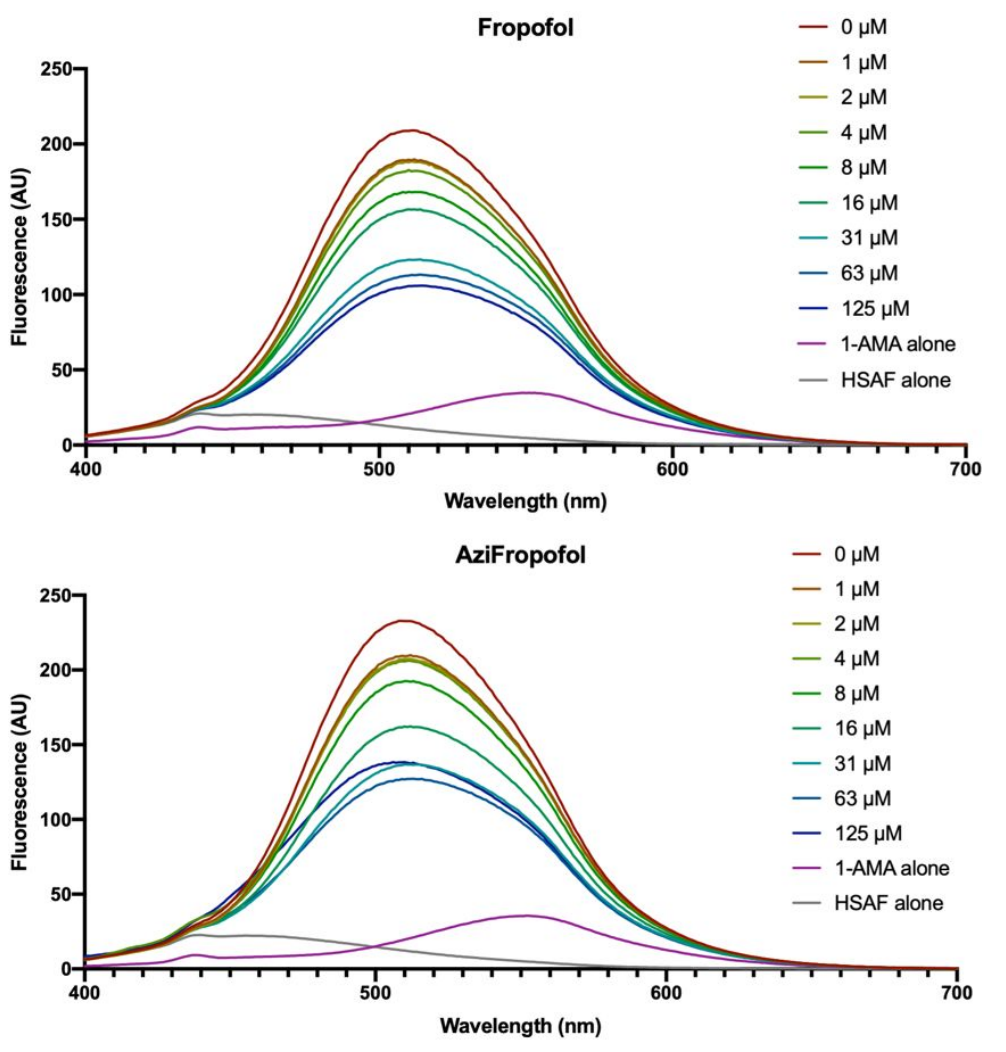

Supplemental Figure $\mathbf{S 1 0}$. Fluorescence spectra of 1AMA competition assays with AziFo and Fropofol. Each plot is the average of three technical replicates at the concentrations of compound indicated in the figure legends. 1-AMA and HSAF controls were subtracted before plotting (see Figure 2 in the main text). 
41

SSQIRQNYST

51

61

71

81

DVALEGVCHF

FRELAEEKRE

GAERLLKMQN

101

111

QRGGRALFQD

LQKPSQDEWG TTLDAMKAAI

VLEKSLNOAL IDLHALGSAQ

151

161

121 131

141

IQRLVGSQAG LGEYLFERLT LKHD

Figure S11. HSAF Sequence Coverage. The sequence shown is that of horse ferritin light chain (UniProt P02791). Bolded regions are those not detected during MS/MS sequencing analysis of photolabeling experiment with $100 \mu \mathrm{M}$ AziFo. Total sequence coverage was $78.7 \%$ (34 of 174 amino acids were not detected). 


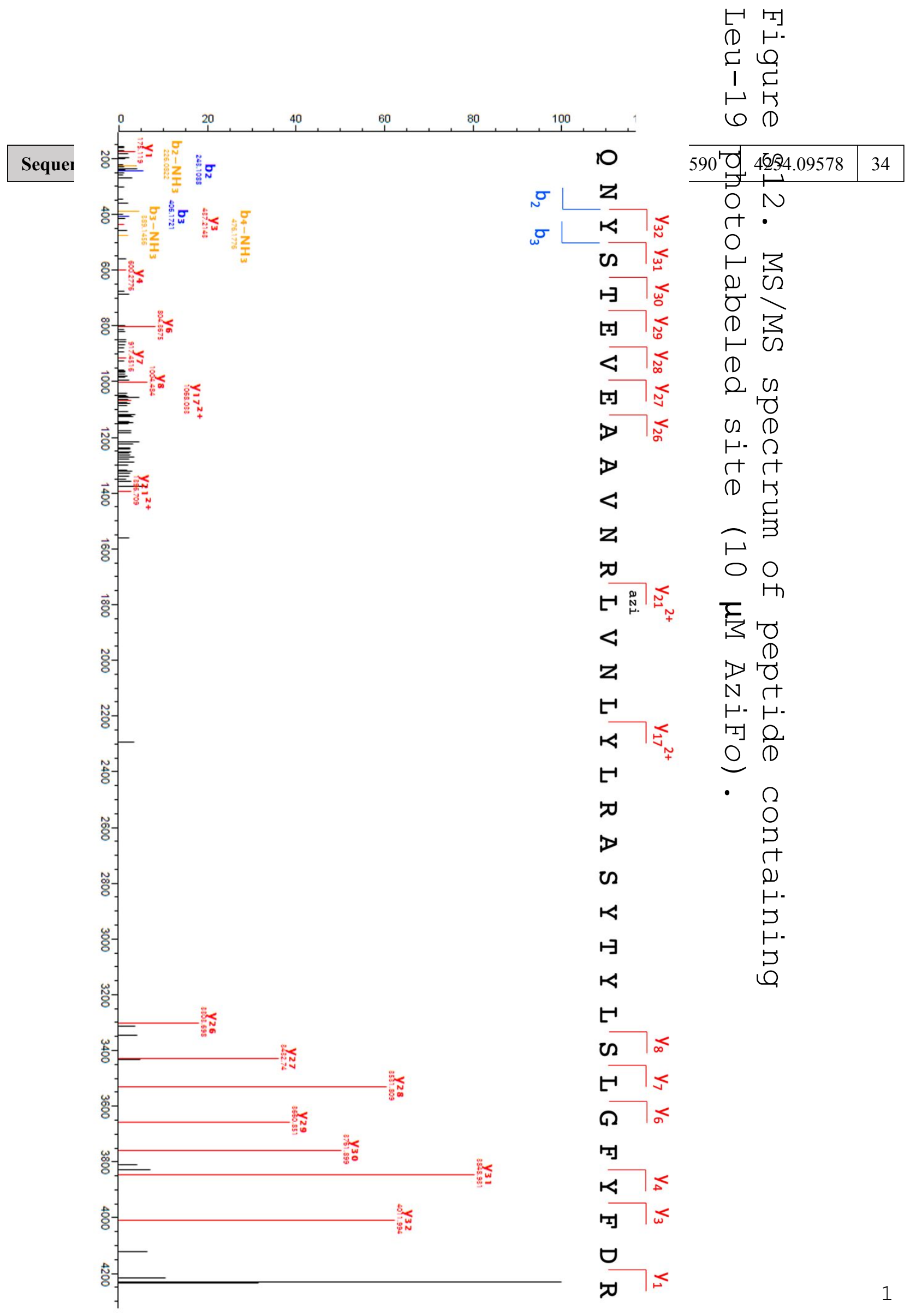




\begin{tabular}{|l|l|l|l|l|}
\hline N & $\mathbf{2}$ & $\mathbf{2 4 3 . 1 0 8 8 3}$ & 4126.03720 & 33 \\
\hline Y & $\mathbf{3}$ & $\mathbf{4 0 6 . 1 7 2 1 5}$ & $\mathbf{4 0 1 1 . 9 9 4 2 7}$ & $\mathbf{3 2}$ \\
\hline S & 4 & 493.20418 & $\mathbf{3 8 4 8 . 9 3 0 9 4}$ & $\mathbf{3 1}$ \\
\hline $\mathrm{T}$ & 5 & 594.25186 & $\mathbf{3 7 6 1 . 8 9 8 9 2}$ & $\mathbf{3 0}$ \\
\hline $\mathrm{E}$ & $\mathbf{6}$ & 723.29445 & $\mathbf{3 6 6 0 . 8 5 1 2 4}$ & $\mathbf{2 9}$ \\
\hline $\mathrm{V}$ & 7 & 822.36287 & $\mathbf{3 5 3 1 . 8 0 8 6 5}$ & $\mathbf{2 8}$ \\
\hline E & 8 & 951.40546 & $\mathbf{3 4 3 2 . 7 4 0 2 3}$ & $\mathbf{2 7}$ \\
\hline $\mathrm{A}$ & 9 & 1022.44257 & $\mathbf{3 3 0 3 . 6 9 7 6 4}$ & $\mathbf{2 6}$ \\
\hline $\mathrm{A}$ & 10 & 1093.47969 & 3232.66053 & 25 \\
\hline V & 11 & 1192.54810 & 3161.62341 & 24 \\
\hline N & 12 & 1306.59103 & 3062.55500 & 23 \\
\hline R & 13 & 1462.69214 & 2948.51207 & 22 \\
\hline Laxi & $\mathbf{1 4}$ & $\mathbf{1 7 9 3 . 8 4 8 0 0}$ & $\mathbf{2 7 9 2 . 4 1 0 9 6}$ & $\mathbf{2 1}$ \\
\hline V & 15 & 1892.91642 & 2461.25510 & 20 \\
\hline N & 16 & 2006.95934 & 2362.18668 & 19 \\
\hline L & 17 & 2120.04341 & 2248.14376 & 18 \\
\hline Sequence & B ions & Y ions & \\
\hline
\end{tabular}

\begin{tabular}{|l|l|l|l|l|}
\hline Y & 18 & 2283.10673 & $\mathbf{2 1 3 5 . 0 5 9 6 9}$ & $\mathbf{1 7}$ \\
\hline L & 19 & 2396.19080 & 1971.99636 & 16 \\
\hline R & 20 & 2552.29191 & 1858.91230 & 15 \\
\hline A & 21 & 2623.32902 & 1702.81119 & 14 \\
\hline S & 22 & 2710.36105 & 1631.77408 & 13 \\
\hline Y & 23 & 2873.42438 & 1544.74205 & 12 \\
\hline T & 24 & 2974.47206 & 1381.67872 & 11 \\
\hline Y & 25 & 3137.53539 & 1280.63104 & 10 \\
\hline L & 26 & 3250.61945 & 1117.65771 & 9 \\
\hline S & 27 & 3337.65148 & $\mathbf{1 0 0 4 . 4 8 3 6 5}$ & $\mathbf{8}$ \\
\hline L & 28 & 3450.73554 & $\mathbf{9 1 7 . 4 5 1 6 2}$ & 7 \\
\hline G & 29 & 3507.75700 & $\mathbf{8 0 4 . 3 6 7 5 6}$ & $\mathbf{6}$ \\
\hline F & 30 & 3654.82542 & 747.34609 & 5 \\
\hline Y & 31 & 3817.88875 & $\mathbf{6 0 0 . 2 7 7 6 8}$ & $\mathbf{4}$ \\
\hline F & 32 & 3964.95716 & $\mathbf{4 3 7 . 2 1 4 3 5}$ & $\mathbf{3}$ \\
\hline D & 33 & 4079.98410 & 290.14594 & 2 \\
\hline R & 34 & 4236.08521 & $\mathbf{1 7 5 . 1 1 9 0 0}$ & $\mathbf{1}$ \\
\hline
\end{tabular}

Table S1. Ion fragmentation table for peptide containing Leu-19 site (10 $\boldsymbol{\mu M}$ AziFo). Peptide is 34 amino acids in length and consists of amino acids 6-39 in the HSAF sequence. Fragmentation ions identified in Figure S12 are indicated in bold (b ions in highlighted in blue and y-ions in red). AziFo modification indicated with superscript 'azi.' 


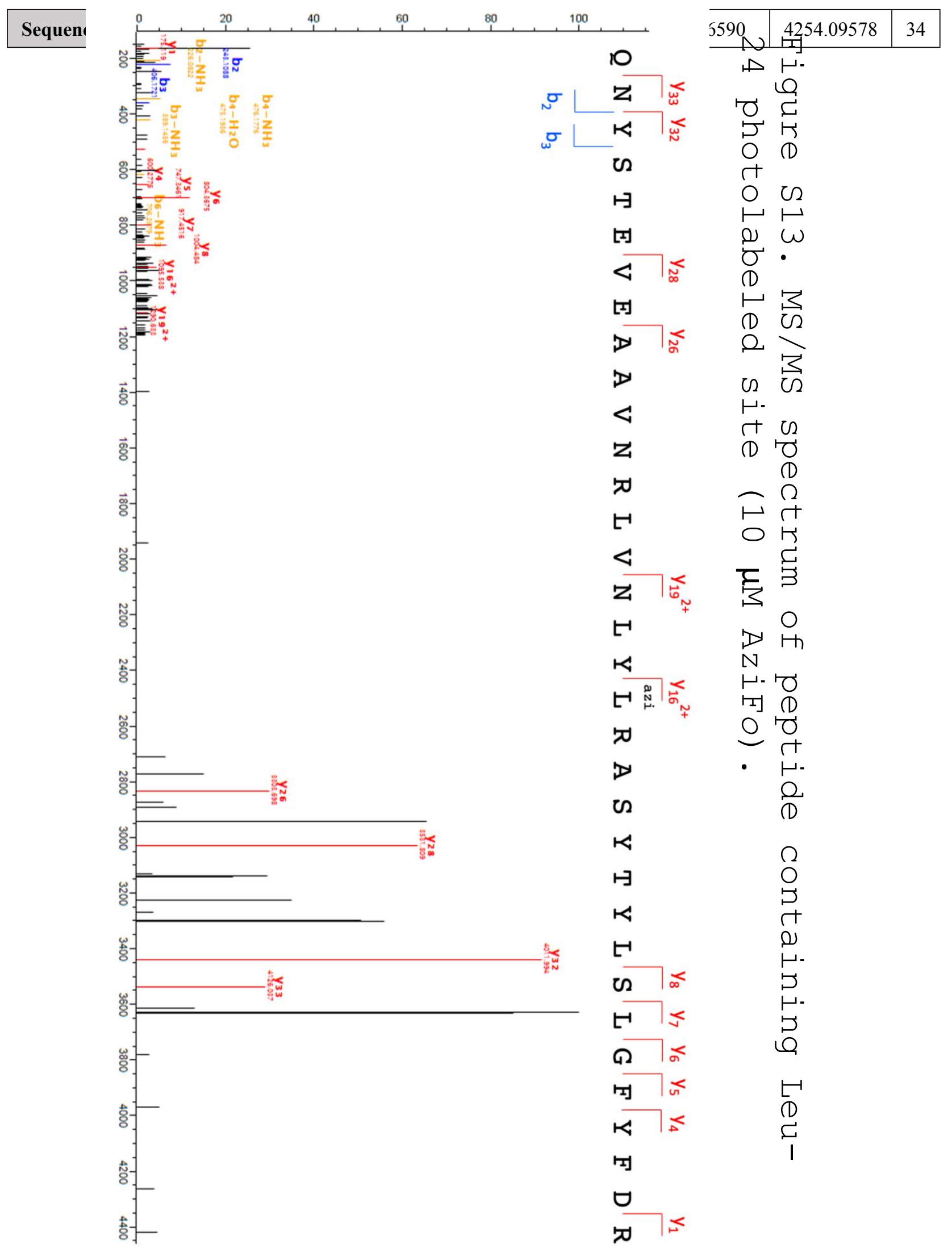




\begin{tabular}{|l|l|l|l|l|}
\hline N & $\mathbf{2}$ & $\mathbf{2 4 3 . 1 0 8 8 3}$ & $\mathbf{4 1 2 6 . 0 3 7 2 0}$ & $\mathbf{3 3}$ \\
\hline $\mathrm{Y}$ & $\mathbf{3}$ & $\mathbf{4 0 6 . 1 7 2 1 5}$ & $\mathbf{4 0 1 1 . 9 9 4 2 7}$ & $\mathbf{3 2}$ \\
\hline $\mathrm{S}$ & 4 & 493.20418 & 3848.93094 & 31 \\
\hline $\mathrm{T}$ & 5 & 594.25186 & 3761.89892 & 30 \\
\hline $\mathrm{E}$ & 6 & 723.29445 & 3660.85124 & 29 \\
\hline $\mathrm{V}$ & 7 & 822.36287 & $\mathbf{3 5 3 1 . 8 0 8 6 5}$ & $\mathbf{2 8}$ \\
\hline $\mathrm{E}$ & 8 & 951.40546 & 3432.74023 & 27 \\
\hline $\mathrm{A}$ & 9 & 1022.44257 & $\mathbf{3 3 0 3 . 6 9 7 6 4}$ & $\mathbf{2 6}$ \\
\hline $\mathrm{A}$ & 10 & 1093.47969 & 3232.66053 & 25 \\
\hline $\mathrm{V}$ & 11 & 1192.54810 & 3161.62341 & 24 \\
\hline $\mathrm{N}$ & 12 & 1306.59103 & 3062.55500 & 23 \\
\hline $\mathrm{R}$ & 13 & 1462.69214 & 2948.51207 & 22 \\
\hline L & 14 & 1575.77620 & 2792.41096 & 21 \\
\hline V & 15 & 1674.84462 & 2679.32690 & 20 \\
\hline N & 16 & 1788.88754 & $\mathbf{2 5 8 0 . 2 5 8 4 8}$ & $\mathbf{1 9}$ \\
\hline L & 17 & 1901.97161 & 2466.21556 & 18 \\
\hline Sequence & B ions & Y ions & \\
\hline
\end{tabular}

\begin{tabular}{|l|l|l|l|l|}
\hline Y & 18 & 2065.03493 & 2353.13149 & 17 \\
\hline L $^{\text {azi }}$ & 19 & 2396.19080 & $\mathbf{2 1 9 0 . 0 6 8 1 6}$ & $\mathbf{1 6}$ \\
\hline R & 20 & 2552.29191 & 1858.91230 & 15 \\
\hline A & 21 & 2623.32902 & 1702.81119 & 14 \\
\hline S & 22 & 2710.36105 & 1631.77408 & 13 \\
\hline Y & 23 & 2873.42438 & 1544.74205 & 12 \\
\hline T & 24 & 2974.47206 & 1381.67872 & 11 \\
\hline Y & 25 & 3137.53539 & 1280.63104 & 10 \\
\hline L & 26 & 3250.61945 & 1117.56771 & 9 \\
\hline S & 27 & 3337.65148 & $\mathbf{1 0 0 4 . 4 8 3 6 5}$ & $\mathbf{8}$ \\
\hline L & 28 & 3450.73554 & $\mathbf{9 1 7 . 4 6 1 6 2}$ & 7 \\
\hline G & 29 & 3507.75700 & $\mathbf{8 0 4 . 3 6 7 5 6}$ & $\mathbf{6}$ \\
\hline F & 30 & 3654.82542 & $\mathbf{7 4 7 . 3 4 6 0 9}$ & $\mathbf{5}$ \\
\hline Y & 31 & 3817.88875 & $\mathbf{6 0 0 . 2 7 7 6 8}$ & $\mathbf{4}$ \\
\hline F & 32 & 3964.95716 & 437.21435 & 3 \\
\hline D & 33 & 4079.98410 & 290.14594 & 2 \\
\hline R & 34 & 4236.08521 & $\mathbf{1 7 5 . 1 1 9 0 0}$ & $\mathbf{1}$ \\
\hline
\end{tabular}

Table S2. Ion fragmentation table for peptide containing Leu-24 site (10 $\boldsymbol{\mu M}$ AziFo). Peptide is 34 amino acids in length and consists of amino acids 6-39 in the HSAF sequence. Fragmentation ions identified in Figure S13 are indicated in bold (b ions in highlighted in blue and y-ions in red). AziFo modification indicated with superscript 'azi.' 


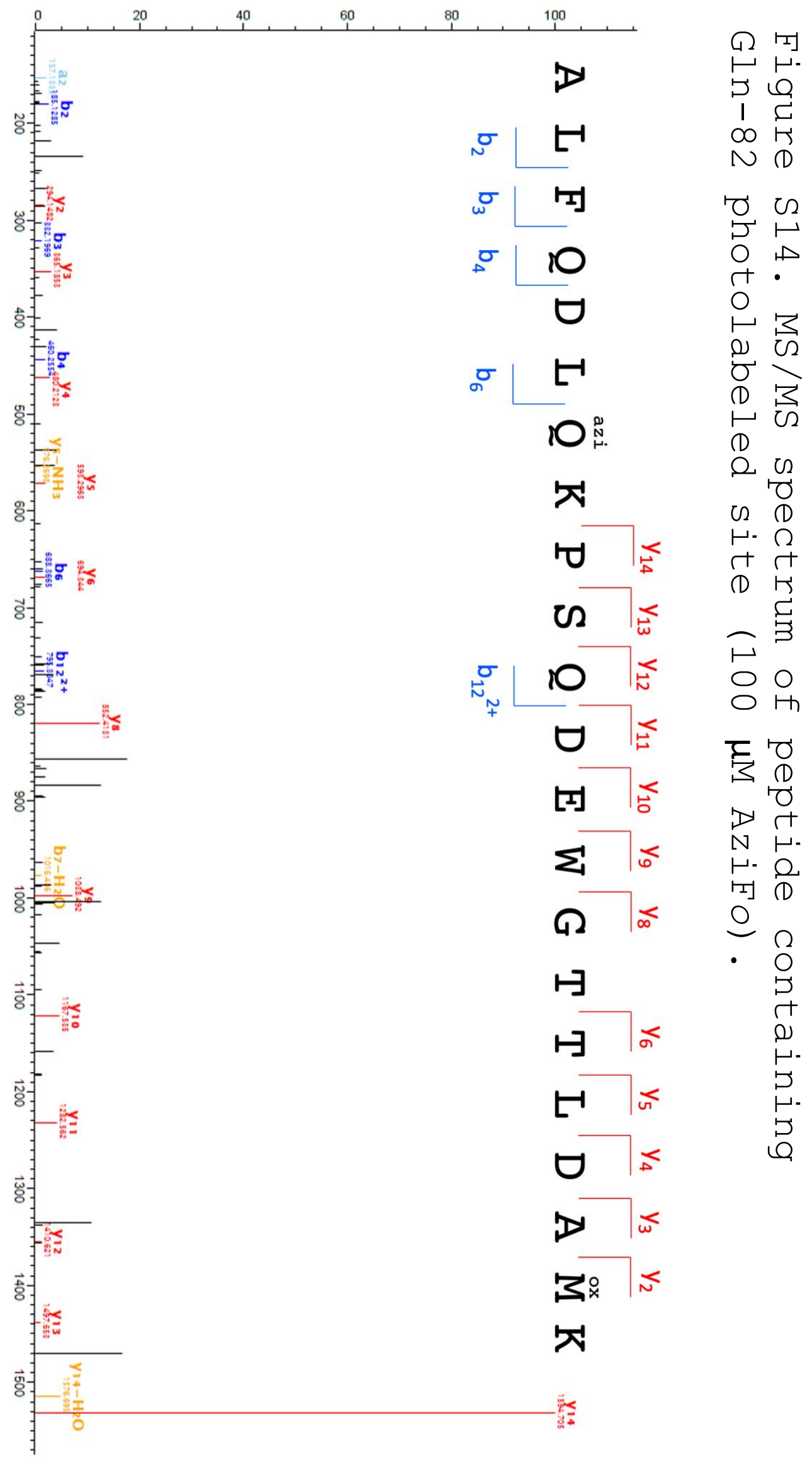




\begin{tabular}{|c|c|c|c|c|}
\hline \multirow{2}{*}{$\begin{array}{l}\text { Sequenc } \\
\text { e } \\
\text { A }\end{array}$} & \multicolumn{2}{|c|}{ B ions } & \multicolumn{2}{|l|}{$Y$ ions } \\
\hline & 1 & 72.04444 & $\begin{array}{l}2756.289 \\
91\end{array}$ & $\begin{array}{l}2 \\
2\end{array}$ \\
\hline L & 2 & $\begin{array}{l}185.1285 \\
0\end{array}$ & $\begin{array}{l}2685.252 \\
79\end{array}$ & $\begin{array}{l}2 \\
1\end{array}$ \\
\hline $\mathrm{F}$ & 3 & $\begin{array}{l}332.1969 \\
1\end{array}$ & $\begin{array}{l}2572.168 \\
73\end{array}$ & $\begin{array}{l}2 \\
0\end{array}$ \\
\hline Q & 4 & $\begin{array}{l}460.2554 \\
9\end{array}$ & $\begin{array}{l}2425.100 \\
31\end{array}$ & $\begin{array}{l}1 \\
9\end{array}$ \\
\hline $\mathrm{D}$ & 5 & $\begin{array}{l}575.2824 \\
3\end{array}$ & $\begin{array}{l}2297.041 \\
74\end{array}$ & $\begin{array}{l}1 \\
8\end{array}$ \\
\hline L & 6 & $\begin{array}{l}688.3665 \\
0\end{array}$ & $\begin{array}{l}2182.014 \\
79\end{array}$ & $\begin{array}{l}1 \\
7\end{array}$ \\
\hline$Q^{a z i}$ & 7 & $\begin{array}{l}1034.496 \\
87\end{array}$ & $\begin{array}{l}2068.930 \\
73\end{array}$ & $\begin{array}{l}1 \\
6\end{array}$ \\
\hline $\mathrm{K}$ & 8 & $\begin{array}{l}1162.591 \\
84\end{array}$ & $\begin{array}{l}1722.800 \\
35\end{array}$ & $\begin{array}{l}1 \\
5\end{array}$ \\
\hline $\mathrm{P}$ & 9 & $\begin{array}{l}1259.644 \\
60\end{array}$ & $\begin{array}{l}1594.705 \\
39\end{array}$ & $\begin{array}{l}1 \\
4\end{array}$ \\
\hline S & $\begin{array}{l}1 \\
0\end{array}$ & $\begin{array}{l}1346.676 \\
63\end{array}$ & $\begin{array}{l}1497.652 \\
63\end{array}$ & $\begin{array}{l}1 \\
3\end{array}$ \\
\hline Q & $\begin{array}{l}1 \\
1\end{array}$ & $\begin{array}{l}1474.735 \\
20\end{array}$ & $\begin{array}{l}1410.620 \\
60\end{array}$ & $\begin{array}{l}1 \\
2\end{array}$ \\
\hline D & $\begin{array}{l}1 \\
2\end{array}$ & $\begin{array}{l}1589.762 \\
15\end{array}$ & $\begin{array}{l}1282.562 \\
02\end{array}$ & $\begin{array}{l}1 \\
1\end{array}$ \\
\hline $\mathrm{E}$ & $\begin{array}{l}1 \\
3\end{array}$ & $\begin{array}{l}1718.804 \\
74\end{array}$ & $\begin{array}{l}1167.535 \\
08\end{array}$ & $\begin{array}{l}1 \\
0\end{array}$ \\
\hline W & $\begin{array}{l}1 \\
4\end{array}$ & $\begin{array}{l}1904.884 \\
05\end{array}$ & $\begin{array}{l}1038.492 \\
49\end{array}$ & 9 \\
\hline G & $\begin{array}{l}1 \\
5\end{array}$ & $\begin{array}{l}1961.905 \\
52\end{array}$ & $\begin{array}{l}852.4131 \\
7\end{array}$ & 8 \\
\hline $\mathrm{T}$ & $\begin{array}{l}1 \\
6\end{array}$ & $\begin{array}{l}2164.000 \\
87\end{array}$ & $\begin{array}{l}795.3917 \\
1\end{array}$ & 7 \\
\hline $\mathrm{T}$ & $\begin{array}{l}1 \\
7\end{array}$ & $\begin{array}{l}2277.084 \\
94\end{array}$ & $\begin{array}{l}694.3440 \\
3\end{array}$ & 6 \\
\hline L & $\begin{array}{l}1 \\
8\end{array}$ & $\begin{array}{l}2277.084 \\
94\end{array}$ & $\begin{array}{l}593.2963 \\
5\end{array}$ & 5 \\
\hline $\mathrm{D}$ & $\begin{array}{l}1 \\
9\end{array}$ & $\begin{array}{l}2392.111 \\
88\end{array}$ & $\begin{array}{l}480.2122 \\
9\end{array}$ & 4 \\
\hline A & $\begin{array}{l}2 \\
0\end{array}$ & $\begin{array}{l}2463.148 \\
99\end{array}$ & $\begin{array}{l}365.1853 \\
5\end{array}$ & 3 \\
\hline
\end{tabular}




\begin{tabular}{|l|l|l|l|l|}
\hline $\mathbf{M}^{\text {ox }}$ & 2 & 2610.184 & 294.1482 & 2 \\
& 1 & 38 & 3 & \\
\hline$K$ & 2 & 2738.279 & 147.1128 & 1 \\
& 2 & 34 & 5 & \\
\hline
\end{tabular}

Table S3. Ion fragmentation table for peptide containing Gln-82 site (100 $\boldsymbol{\mu M}$ AziFo). Peptide is 22 amino acids in length and consists of amino acids 76-97 in the HSAF sequence. Fragmentation ions identified in Figure S14 are indicated in bold ( $b$ ions in highlighted in blue and y-ions in red). AziFo modification indicated with superscript 'azi.' Methionine oxidation is indicated with superscript 'ox.' 


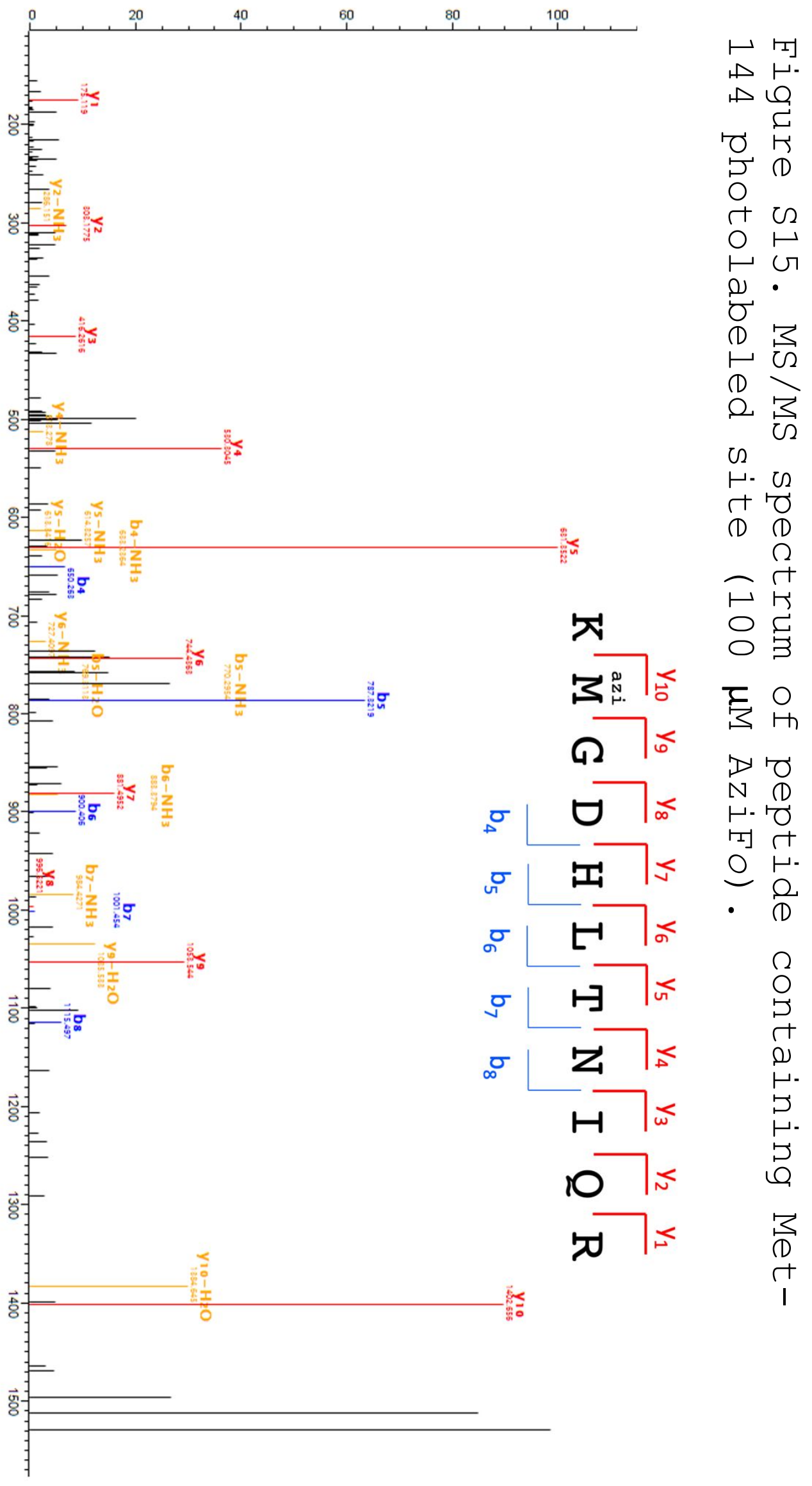




\begin{tabular}{|l|l|l|l|l|}
\hline Sequence & \multicolumn{2}{|l|}{ B ions } & \multicolumn{2}{l|}{ Y ions } \\
\hline K & 1 & 129.10228 & 1530.75087 & 11 \\
\hline$M^{\text {azi }}$ & 2 & 478.21457 & $\mathbf{1 4 0 2 . 6 5 5 9 1}$ & $\mathbf{1 0}$ \\
\hline G & 3 & 535.23603 & $\mathbf{1 0 5 3 . 5 4 3 6 2}$ & $\mathbf{9}$ \\
\hline D & 4 & $\mathbf{6 5 0 . 2 6 2 9 8}$ & $\mathbf{9 9 6 . 5 2 2 1 6}$ & $\mathbf{8}$ \\
\hline H & $\mathbf{5}$ & $\mathbf{7 8 7 . 3 2 1 8 9}$ & $\mathbf{8 8 1 . 4 9 5 2 2}$ & 7 \\
\hline L & $\mathbf{6}$ & $\mathbf{9 0 0 . 4 0 5 9 5}$ & $\mathbf{7 4 4 . 4 3 6 3 1}$ & $\mathbf{6}$ \\
\hline T & 7 & $\mathbf{1 0 0 1 . 4 5 3 6 3}$ & $\mathbf{6 3 1 . 3 5 2 2 4}$ & $\mathbf{5}$ \\
\hline $\mathrm{N}$ & $\mathbf{8}$ & $\mathbf{1 1 1 5 . 4 9 6 5 6}$ & $\mathbf{5 3 0 . 3 0 4 5 6}$ & $\mathbf{4}$ \\
\hline $\mathrm{I}$ & 9 & 1228.58062 & $\mathbf{4 1 6 . 2 6 1 6 4}$ & $\mathbf{3}$ \\
\hline $\mathrm{Q}$ & 10 & 1356.63920 & $\mathbf{3 0 3 . 1 7 7 5 7}$ & $\mathbf{2}$ \\
\hline $\mathrm{R}$ & 11 & 1512.74031 & $\mathbf{1 7 5 . 1 1 9 0 0}$ & $\mathbf{1}$ \\
\hline
\end{tabular}

Table S4. Ion fragmentation table for peptide containing Met-144 site (100 $\mu$ M AziFo). Peptide is 11 amino acids in length and consists of amino acids 143-153 in the HSAF sequence. Fragmentation ions identified in Figure S15 are indicated in bold (b ions in highlighted in blue and y-ions in red). AziFo modification indicated with superscript 'azi.' 


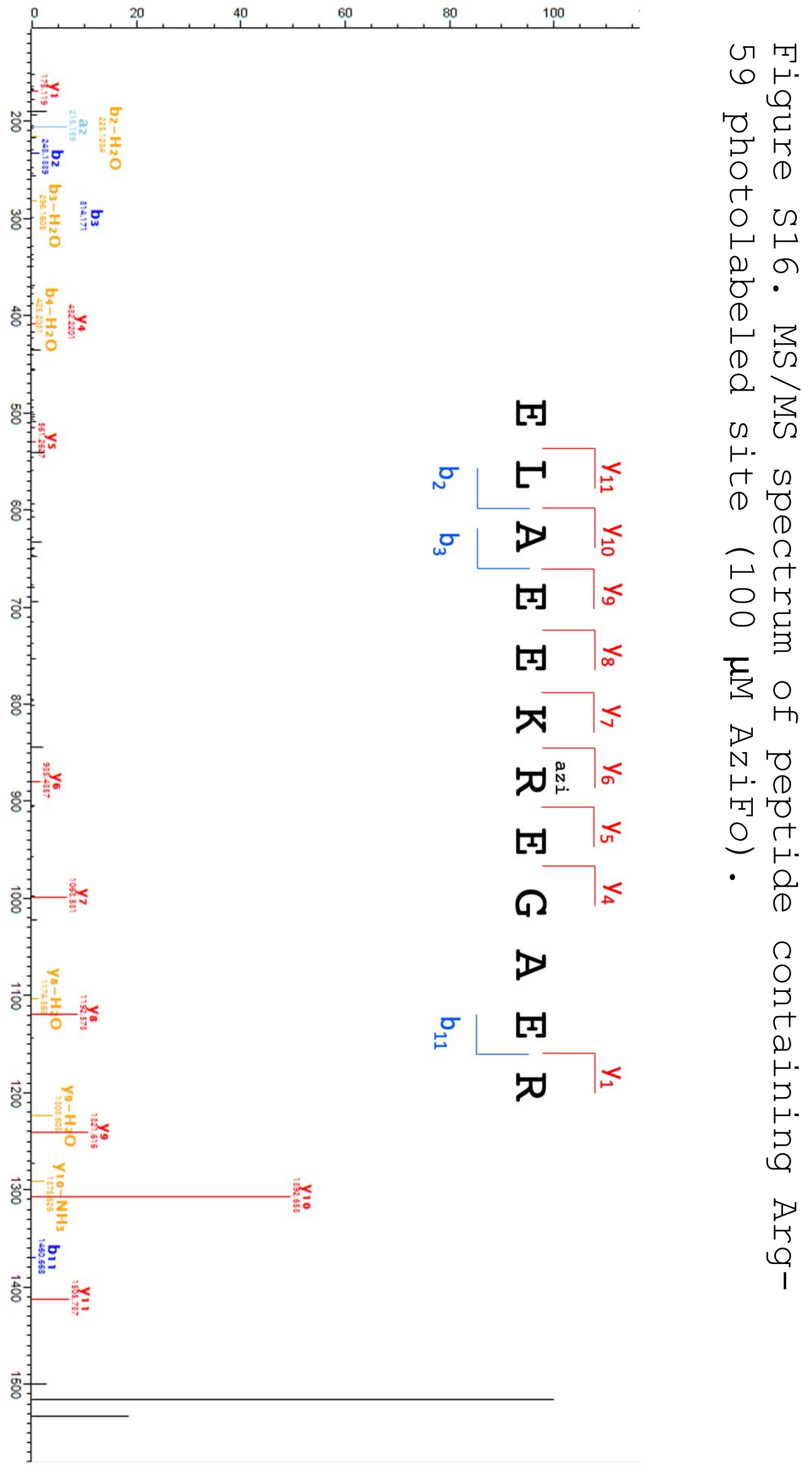




\begin{tabular}{|l|l|l|l|l|}
\hline Sequence & \multicolumn{2}{|l|}{ B ions } & \multicolumn{2}{l}{ Y ions } \\
\hline E & 1 & 130.04991 & 1634.77959 & 12 \\
\hline L & 2 & 243.13398 & $\mathbf{1 5 0 5 . 7 3 7 0 0}$ & $\mathbf{1 1}$ \\
\hline A & $\mathbf{3}$ & 314.17109 & $\mathbf{1 3 9 2 . 6 5 2 9 3}$ & $\mathbf{1 0}$ \\
\hline E & 4 & 443.21368 & $\mathbf{1 3 2 1 . 6 1 5 8 2}$ & $\mathbf{9}$ \\
\hline E & 5 & 572.25628 & $\mathbf{1 1 9 2 . 5 7 3 2 3}$ & $\mathbf{8}$ \\
\hline K & 6 & 700.35124 & $\mathbf{1 0 6 3 . 5 3 0 6 3}$ & 7 \\
\hline$R^{\text {azi }}$ & 7 & 1074.52415 & $\mathbf{9 3 5 . 4 3 5 6 7}$ & $\mathbf{6}$ \\
\hline E & 8 & 1203.56674 & $\mathbf{5 6 1 . 2 6 2 7 6}$ & $\mathbf{5}$ \\
\hline G & 9 & 1260.58821 & $\mathbf{4 3 2 . 2 2 0 1 7}$ & 4 \\
\hline A & 10 & 1331.62532 & 375.19870 & 3 \\
\hline E & $\mathbf{1 1}$ & $\mathbf{1 4 6 0 . 6 6 7 9 1}$ & 304.16159 & 2 \\
\hline R & 12 & 1616.76902 & 175.11900 & 1 \\
\hline
\end{tabular}

Table S5. Ion fragmentation table for peptide containing Arg-59 site (100 $\mu \mathrm{M}$ AziFo). Peptide is 12 amino acids in length and consists of amino acids 53-64 in the HSAF sequence. Fragmentation ions identified in Figure S16 are indicated in bold (b ions in highlighted in blue and y-ions in red). AziFo modification indicated with superscript 'azi.' 


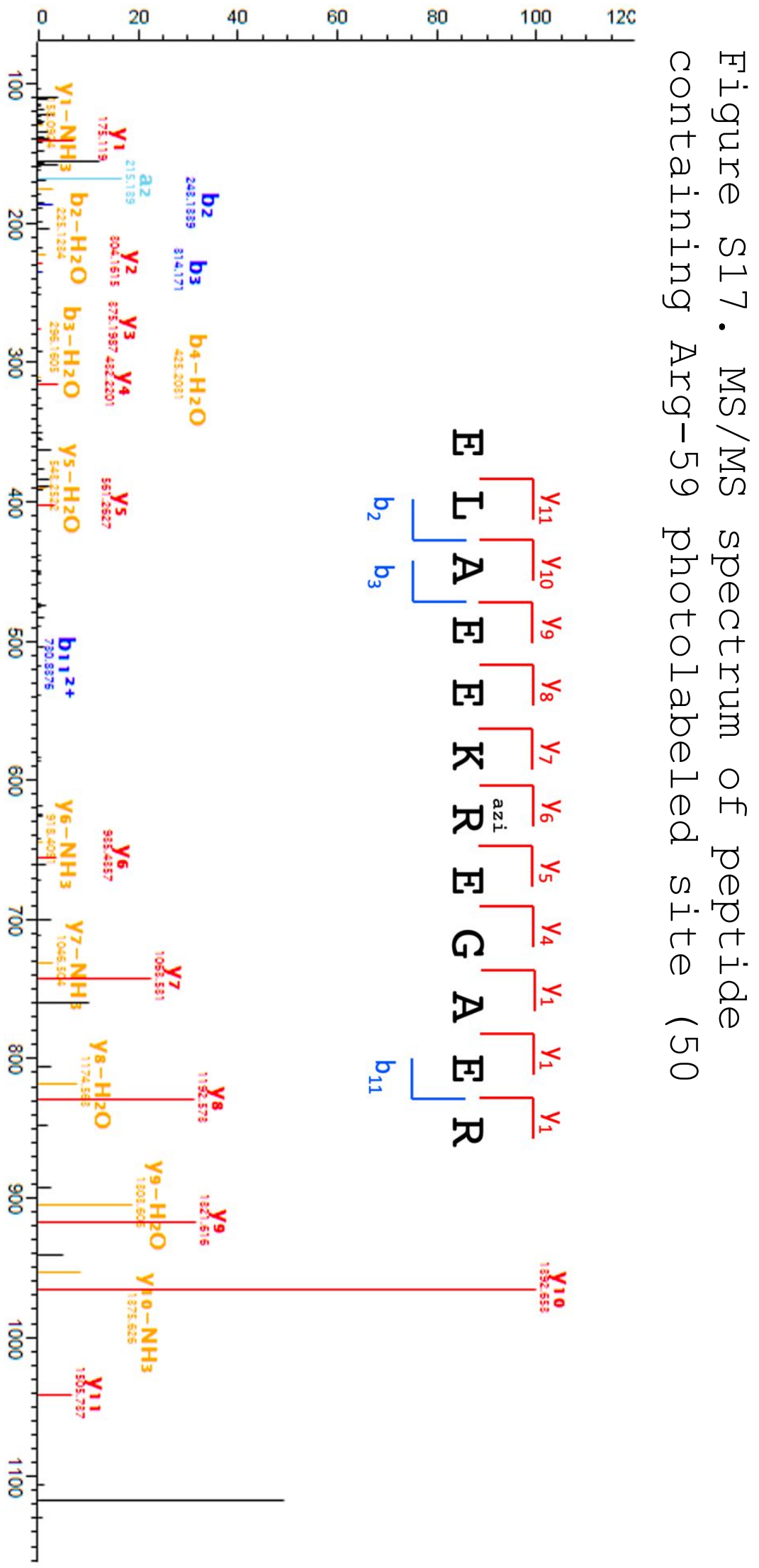




\begin{tabular}{|l|l|l|l|l|}
\hline Sequence & \multicolumn{2}{|l|}{ B ions } & \multicolumn{2}{l|}{ Y ions } \\
\hline E & 1 & 130.04991 & 1634.77959 & 12 \\
\hline L & 2 & 243.13398 & $\mathbf{1 5 0 5 . 7 3 7 0 0}$ & $\mathbf{1 1}$ \\
\hline $\mathrm{A}$ & $\mathbf{3}$ & 314.17109 & $\mathbf{1 3 9 2 . 6 5 2 9 3}$ & $\mathbf{1 0}$ \\
\hline $\mathrm{E}$ & 4 & 443.21368 & $\mathbf{1 3 2 1 . 6 1 5 8 2}$ & $\mathbf{9}$ \\
\hline $\mathrm{E}$ & 5 & 572.25628 & $\mathbf{1 1 9 2 . 5 7 3 2 3}$ & $\mathbf{8}$ \\
\hline $\mathrm{K}$ & 6 & 700.35124 & $\mathbf{1 0 6 3 . 5 3 0 6 3}$ & $\mathbf{7}$ \\
\hline $\mathbf{R}^{\text {axi }}$ & $\mathbf{7}$ & 1074.52415 & $\mathbf{9 3 5 . 4 3 5 6 7}$ & $\mathbf{6}$ \\
\hline E & 8 & 1203.56674 & $\mathbf{5 6 1 . 2 6 2 7 6}$ & $\mathbf{5}$ \\
\hline $\mathrm{G}$ & 9 & 1260.58821 & $\mathbf{4 3 2 . 2 2 0 1 7}$ & 4 \\
\hline $\mathrm{A}$ & 10 & 1331.62532 & $\mathbf{3 7 5 . 1 9 8 7 0}$ & $\mathbf{3}$ \\
\hline E & $\mathbf{1 1}$ & $\mathbf{1 4 6 0 . 6 6 7 9 1}$ & $\mathbf{3 0 4 . 1 6 1 5 9}$ & $\mathbf{2}$ \\
\hline $\mathrm{R}$ & 12 & 1616.76902 & $\mathbf{1 7 5 . 1 1 9 0 0}$ & $\mathbf{1}$ \\
\hline
\end{tabular}

Table S6. Ion fragmentation table for peptide containing Arg-59 site (50 $\mu \mathrm{M}$ AziFo). Peptide is 12 amino acids in length and consists of amino acids 53-64 in the HSAF sequence. Fragmentation ions identified in Figure 5 (in the main text) are indicated in bold (b ions in highlighted in blue and y-ions in red). AziFo modification indicated with superscript 'azi.' 


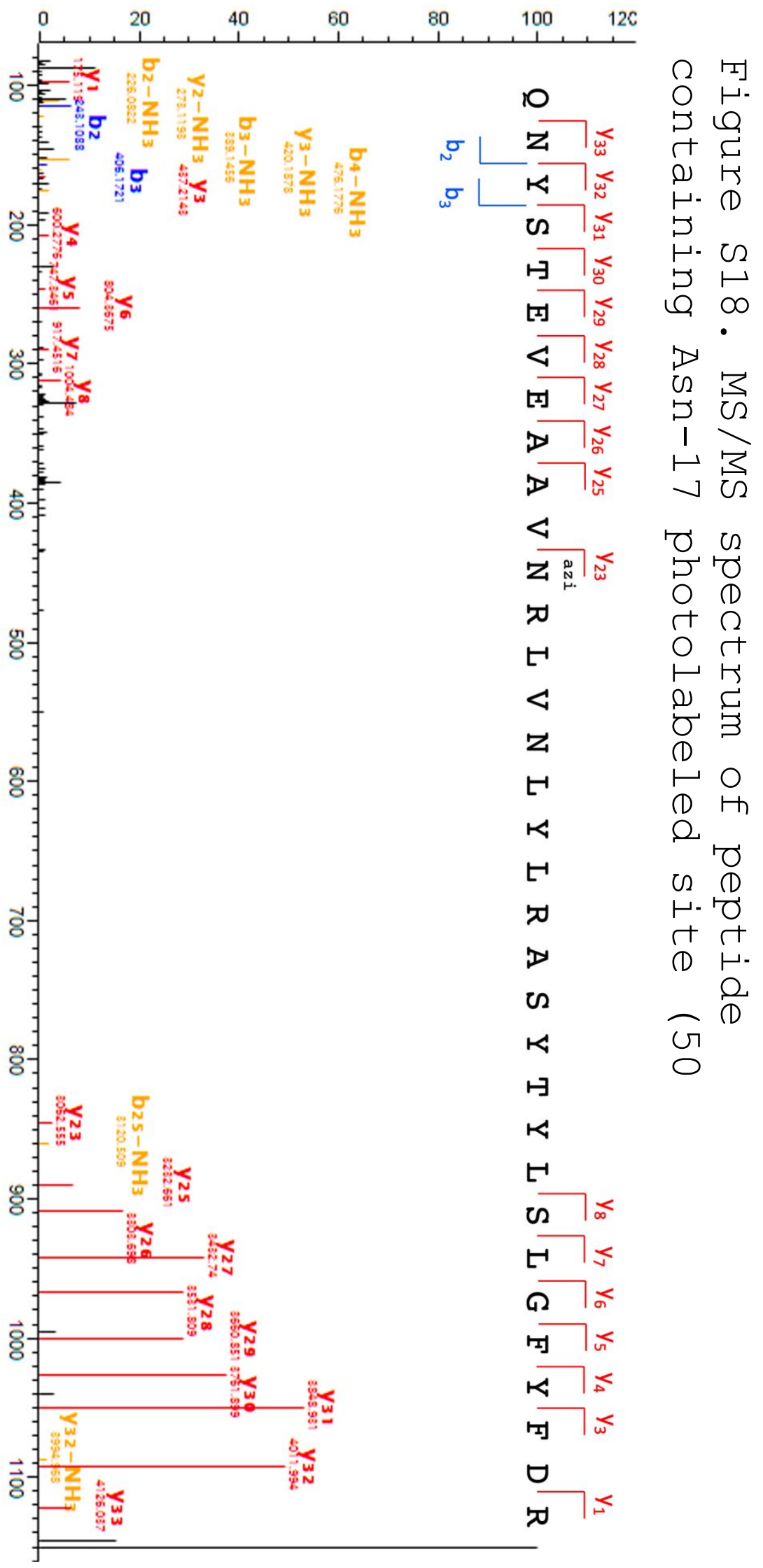




\begin{tabular}{|c|c|c|c|c|}
\hline Sequence & \multicolumn{2}{|c|}{$\mathrm{B}$ ions } & \multicolumn{2}{|l|}{ Y ions } \\
\hline Q & 1 & $\begin{array}{l}129.065 \\
90\end{array}$ & $\begin{array}{l}4254.09 \\
578\end{array}$ & $\begin{array}{l}3 \\
4\end{array}$ \\
\hline $\mathrm{N}$ & 2 & $\begin{array}{l}243.108 \\
83\end{array}$ & $\begin{array}{l}4126.03 \\
720\end{array}$ & $\begin{array}{l}3 \\
3\end{array}$ \\
\hline Y & 3 & $\begin{array}{l}406.172 \\
15\end{array}$ & $\begin{array}{l}4011.99 \\
427\end{array}$ & $\begin{array}{l}3 \\
2\end{array}$ \\
\hline S & 4 & $\begin{array}{l}493.204 \\
18\end{array}$ & $\begin{array}{l}3848.93 \\
094\end{array}$ & $\begin{array}{l}3 \\
1\end{array}$ \\
\hline $\mathrm{T}$ & 5 & $\begin{array}{l}594.251 \\
86\end{array}$ & $\begin{array}{l}3761.89 \\
892\end{array}$ & $\begin{array}{l}3 \\
0\end{array}$ \\
\hline E & 6 & $\begin{array}{l}723.294 \\
45\end{array}$ & $\begin{array}{l}3660.85 \\
124\end{array}$ & $\begin{array}{l}2 \\
9\end{array}$ \\
\hline V & 7 & $\begin{array}{l}822.362 \\
87\end{array}$ & $\begin{array}{l}3531.80 \\
865\end{array}$ & $\begin{array}{l}2 \\
8\end{array}$ \\
\hline E & 8 & $\begin{array}{l}951.405 \\
46\end{array}$ & $\begin{array}{l}3432.74 \\
023\end{array}$ & $\begin{array}{l}2 \\
7\end{array}$ \\
\hline A & 9 & $\begin{array}{l}1022.44 \\
257\end{array}$ & $\begin{array}{l}3303.69 \\
764\end{array}$ & $\begin{array}{l}2 \\
6\end{array}$ \\
\hline A & $\begin{array}{l}1 \\
0\end{array}$ & $\begin{array}{l}1093.47 \\
969\end{array}$ & $\begin{array}{l}3232.66 \\
053\end{array}$ & $\begin{array}{l}2 \\
5\end{array}$ \\
\hline V & $\begin{array}{l}1 \\
1\end{array}$ & $\begin{array}{l}1192.54 \\
810\end{array}$ & $\begin{array}{l}3161.62 \\
341\end{array}$ & $\begin{array}{l}2 \\
4\end{array}$ \\
\hline $\mathrm{N}^{\mathrm{azi}}$ & $\begin{array}{l}1 \\
2\end{array}$ & $\begin{array}{l}1524.66 \\
293\end{array}$ & $\begin{array}{l}3062.55 \\
500\end{array}$ & $\begin{array}{l}2 \\
3\end{array}$ \\
\hline $\mathrm{R}$ & $\begin{array}{l}1 \\
3\end{array}$ & $\begin{array}{l}1680.76 \\
404\end{array}$ & $\begin{array}{l}2730.44 \\
027\end{array}$ & $\begin{array}{l}2 \\
2\end{array}$ \\
\hline L & $\begin{array}{l}1 \\
4\end{array}$ & $\begin{array}{l}1793.84 \\
840\end{array}$ & $\begin{array}{l}2574.33 \\
916\end{array}$ & $\begin{array}{l}2 \\
1\end{array}$ \\
\hline V & $\begin{array}{l}1 \\
5\end{array}$ & $\begin{array}{l}1892.91 \\
652\end{array}$ & $\begin{array}{l}2461.25 \\
510\end{array}$ & $\begin{array}{l}2 \\
0\end{array}$ \\
\hline $\mathrm{N}$ & $\begin{array}{l}1 \\
6\end{array}$ & $\begin{array}{l}2006.95 \\
944\end{array}$ & $\begin{array}{l}2362.18 \\
668\end{array}$ & $\begin{array}{l}1 \\
9\end{array}$ \\
\hline L & $\begin{array}{l}1 \\
7\end{array}$ & $\begin{array}{l}2120.04 \\
351\end{array}$ & $\begin{array}{l}2248.14 \\
376\end{array}$ & $\begin{array}{l}1 \\
8\end{array}$ \\
\hline
\end{tabular}

\begin{tabular}{|c|c|c|c|c|}
\hline \multirow{2}{*}{$\begin{array}{l}\text { Sequence } \\
\mathrm{Y}\end{array}$} & \multicolumn{2}{|c|}{ B ions } & \multicolumn{2}{|l|}{$\mathrm{Y}$ ions } \\
\hline & $\begin{array}{l}1 \\
8\end{array}$ & $\begin{array}{l}2283.10 \\
683\end{array}$ & $\begin{array}{l}2135.05 \\
969\end{array}$ & $\begin{array}{l}1 \\
7\end{array}$ \\
\hline L & $\begin{array}{l}1 \\
9\end{array}$ & $\begin{array}{l}2396.19 \\
090\end{array}$ & $\begin{array}{l}1971.99 \\
636\end{array}$ & $\begin{array}{l}1 \\
6\end{array}$ \\
\hline $\mathrm{R}$ & $\begin{array}{l}2 \\
0\end{array}$ & $\begin{array}{l}2552.29 \\
201\end{array}$ & $\begin{array}{l}1858.91 \\
230\end{array}$ & $\begin{array}{l}1 \\
5\end{array}$ \\
\hline A & $\begin{array}{l}2 \\
1\end{array}$ & $\begin{array}{l}2623.32 \\
912\end{array}$ & $\begin{array}{l}1702.81 \\
119\end{array}$ & $\begin{array}{l}1 \\
4\end{array}$ \\
\hline S & $\begin{array}{l}2 \\
2\end{array}$ & $\begin{array}{l}2710.36 \\
115\end{array}$ & $\begin{array}{l}1631.77 \\
408\end{array}$ & $\begin{array}{l}1 \\
3\end{array}$ \\
\hline $\mathrm{Y}$ & $\begin{array}{l}2 \\
3\end{array}$ & $\begin{array}{l}2873.42 \\
448\end{array}$ & $\begin{array}{l}1544.74 \\
205\end{array}$ & $\begin{array}{l}1 \\
2\end{array}$ \\
\hline $\mathrm{T}$ & $\begin{array}{l}2 \\
4\end{array}$ & $\begin{array}{l}2974.47 \\
216\end{array}$ & $\begin{array}{l}1381.67 \\
872\end{array}$ & $\begin{array}{l}1 \\
1\end{array}$ \\
\hline $\mathrm{Y}$ & $\begin{array}{l}2 \\
5\end{array}$ & $\begin{array}{l}3137.53 \\
549\end{array}$ & $\begin{array}{l}1280.63 \\
104\end{array}$ & $\begin{array}{l}1 \\
0\end{array}$ \\
\hline L & $\begin{array}{l}2 \\
6\end{array}$ & $\begin{array}{l}3250.61 \\
955\end{array}$ & $\begin{array}{l}1117.56 \\
771\end{array}$ & 9 \\
\hline S & $\begin{array}{l}2 \\
7\end{array}$ & $\begin{array}{l}3337.65 \\
158\end{array}$ & $\begin{array}{l}1004.48 \\
365\end{array}$ & 8 \\
\hline L & $\begin{array}{l}2 \\
8\end{array}$ & $\begin{array}{l}3450.76 \\
564\end{array}$ & $\begin{array}{l}917.461 \\
62\end{array}$ & 7 \\
\hline G & $\begin{array}{l}2 \\
9\end{array}$ & $\begin{array}{l}3507.75 \\
710\end{array}$ & $\begin{array}{l}804.367 \\
56\end{array}$ & 6 \\
\hline $\mathrm{F}$ & $\begin{array}{l}3 \\
0\end{array}$ & $\begin{array}{l}3654.82 \\
552\end{array}$ & $\begin{array}{l}747.346 \\
09\end{array}$ & 5 \\
\hline $\mathrm{Y}$ & $\begin{array}{l}3 \\
1\end{array}$ & $\begin{array}{l}3817.88 \\
885\end{array}$ & $\begin{array}{l}600.277 \\
68\end{array}$ & 4 \\
\hline $\mathrm{F}$ & $\begin{array}{l}3 \\
2\end{array}$ & $\begin{array}{l}3964.95 \\
726\end{array}$ & $\begin{array}{l}437.214 \\
35\end{array}$ & 3 \\
\hline D & $\begin{array}{l}3 \\
3\end{array}$ & $\begin{array}{l}4079.98 \\
420\end{array}$ & $\begin{array}{l}290.145 \\
94\end{array}$ & 2 \\
\hline $\mathrm{R}$ & $\begin{array}{l}3 \\
4\end{array}$ & $\begin{array}{l}4236.08 \\
531\end{array}$ & $\begin{array}{l}175.119 \\
00\end{array}$ & 1 \\
\hline
\end{tabular}

Table S7. Ion fragmentation table for peptide containing Asn-17 site (50 $\boldsymbol{\mu M}$ AziFo). Peptide is 34 amino acids in length and consists of amino acids 6-39 in the HSAF sequence. Fragmentation ions identified in Figure S18 are indicated in bold (b ions in highlighted in blue and y-ions in red). AziFo modification indicated with superscript 'azi.' 


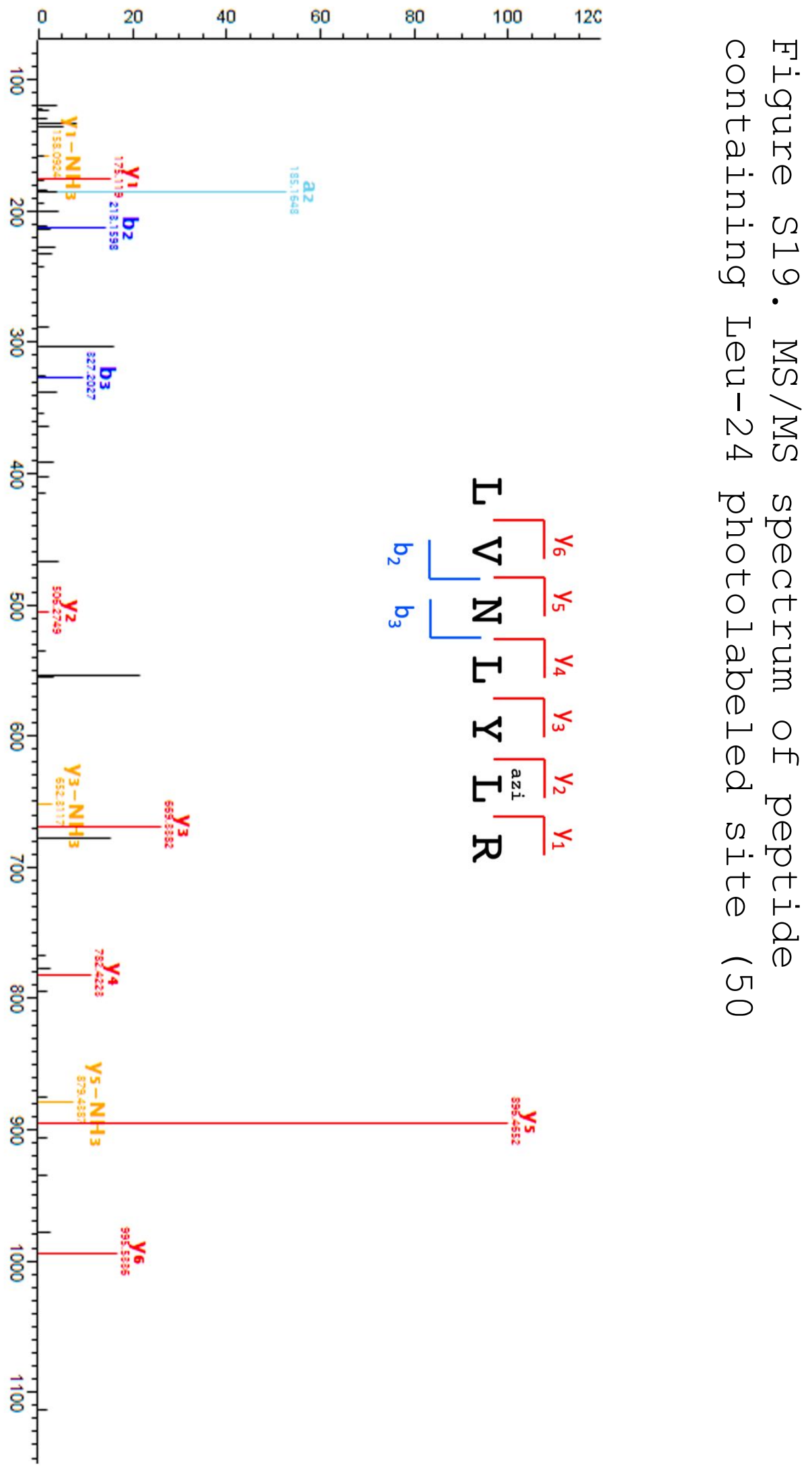




\begin{tabular}{|l|l|l|l|l|}
\hline Sequence & \multicolumn{2}{|l|}{ B ions } & \multicolumn{2}{l|}{ Y ions } \\
\hline L & 1 & 114.09139 & 1151.63615 & 7 \\
\hline V & 2 & 213.15980 & $\mathbf{9 9 5 . 5 3 3 6 9}$ & $\mathbf{6}$ \\
\hline N & 3 & 327.20273 & $\mathbf{8 9 6 . 4 6 5 2 8}$ & $\mathbf{5}$ \\
\hline L $^{\text {azi }}$ & 4 & 440.28679 & $\mathbf{7 8 2 . 4 2 2 6 5}$ & 4 \\
\hline Y & 5 & 603.35012 & $\mathbf{6 6 9 . 3 3 8 2 9}$ & $\mathbf{3}$ \\
\hline L & 6 & 934.50608 & $\mathbf{5 0 6 . 2 7 4 9 6}$ & $\mathbf{2}$ \\
\hline R & 7 & 1090.60719 & $\mathbf{1 7 5 . 1 1 9 0 0}$ & $\mathbf{1}$ \\
\hline
\end{tabular}

Table S8. Ion fragmentation table for peptide containing Leu-24 site (50 $\mu \mathrm{M}$ AziFo). Peptide is 7 amino acids in length and consists of amino acids 19-25 in the HSAF sequence. Fragmentation ions identified in Figure S19 are indicated in bold (b ions in highlighted in blue and y-ions in red). AziFo modification indicated with superscript 'azi.'
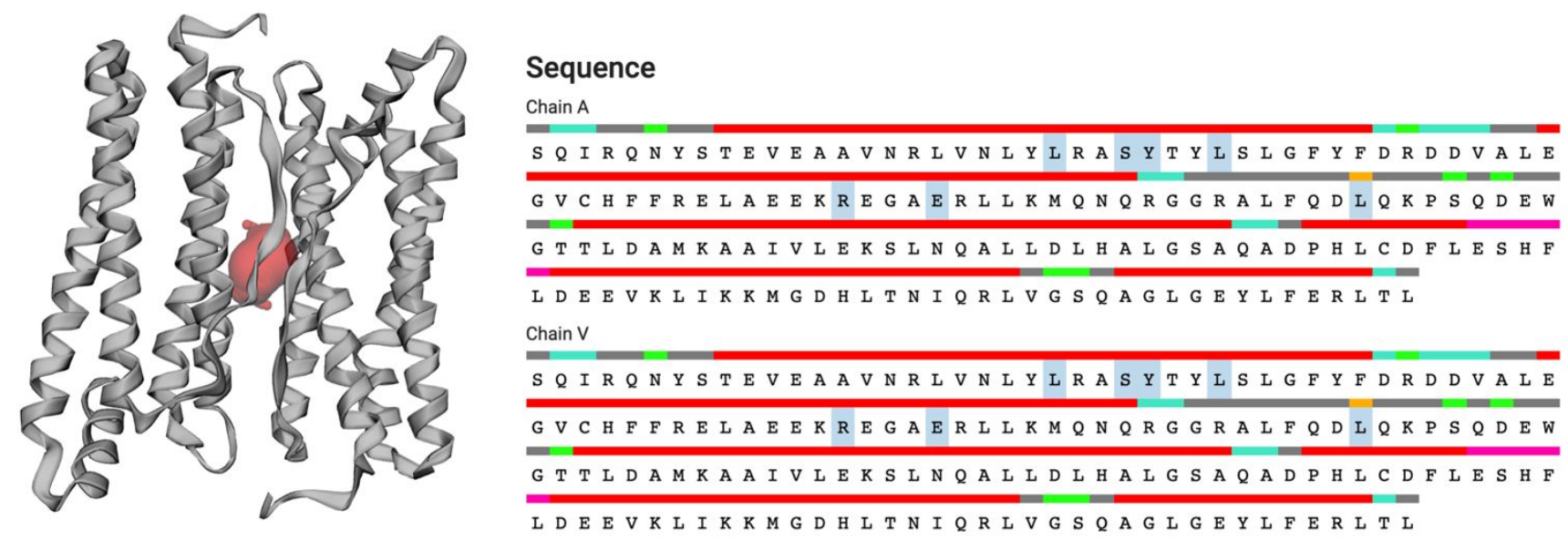

Supplemental Figure S17. CASTp analysis of HSAF. Analysis of the HSAF homodimer protein structure identified the previously described ligand binding pocket and the 7 amino acids lining this pocket are highlighted: L24, S27, Y28, R59, E63, L81. This image is directly from the output provided by CASTp (REF). 


\begin{tabular}{|c|c|c|c|c|c|c|c|c|c|}
\hline & Fropofol & & & AziFo & & & 1-AMA & & \\
\hline mode & $\begin{array}{c}\text { affinity } \\
\text { (kcal/mol) }\end{array}$ & $\begin{array}{l}\text { dist from } \\
\text { rmsd l.b. }\end{array}$ & $\begin{array}{l}\text { best mode } \\
\text { rmsd u.b. }\end{array}$ & $\begin{array}{c}\text { affinity } \\
\text { (kcal/mol) }\end{array}$ & $\begin{array}{l}\text { dist from } \\
\text { rmsd l.b. }\end{array}$ & $\begin{array}{l}\text { best mode } \\
\text { rmsd u.b. }\end{array}$ & $\begin{array}{c}\text { affinity } \\
\text { (kcal/mol) }\end{array}$ & $\begin{array}{l}\text { dist from } \\
\text { rmsd l.b. }\end{array}$ & $\begin{array}{l}\text { best mode } \\
\text { rmsd u.b. }\end{array}$ \\
\hline 1 & -6.9 & 0.000 & 0.000 & -8.1 & 0.000 & 0.000 & -8.5 & 0.000 & 0.000 \\
\hline 2 & -6.9 & 1.928 & 4.734 & -8.1 & 2.615 & 5.071 & -8.5 & 1.693 & 4.891 \\
\hline 3 & -6.9 & 0.055 & 4.533 & -7.5 & 1.438 & 1.734 & -7.7 & 1.463 & 2.450 \\
\hline 4 & -6.9 & 1.914 & 3.122 & -7.4 & 1.624 & 1.994 & -7.7 & 1.912 & 5.399 \\
\hline 5 & -6.7 & 1.625 & 2.386 & -7.3 & 1.862 & 2.328 & -7.1 & 1.956 & 2.393 \\
\hline 6 & -6.7 & 1.726 & 4.650 & -7.2 & 2.920 & 5.195 & -7.1 & 2.277 & 5.139 \\
\hline 7 & -6.7 & 1.607 & 4.846 & -7.2 & 2.887 & 5.225 & -6.2 & 1.986 & 2.900 \\
\hline 8 & -6.5 & 1.515 & 2.071 & -6.7 & 2.925 & 4.930 & -6.2 & 2.367 & 5.154 \\
\hline 9 & -6.5 & 1.891 & 2.994 & -6.4 & 0.815 & 1.499 & -6.1 & 1.749 & 2.127 \\
\hline
\end{tabular}

Supplemental Table S6. Lowest Energy Poses from AutoDock Vina Calculations. This table displays the output of docking simulations generated with AutoDock Vina. Simulations were run with the ligand indicated and a homodimer of HSAF (PDB ID 3f32). The predicted binding affinity for each ligand is given in $\mathrm{kcal} / \mathrm{mol}$. Calculated root-meansquare deviation metrics for lower bound (l.b.) and upper bound (u.b.) are also shown.

SUPPORTING METHODS

1-aminoanthracene extinction coefficient. The UV-Vis spectrum of 1-AMA (1-aminoanthracene, Sigma Aldrich, technical grade) solutions of known concentrations $(7-250 \mu \mathrm{M})$ in pure methanol was measured (Cary 300 Bio UV-Vis spectrophotometer) in a 1 cm path length quartz cuvette. Samples were prepared in triplicate. A spectrum recorded from 200-800 nm showed an intensity maximum at $368 \mathrm{~nm}$. The absorbance at $368 \mathrm{~nm}$ was plotted vs. concentration and, per Beer's law, an extinction coefficient $\left(\Sigma_{368}\right)$ of $4073 \mathrm{M}^{-1} \mathrm{~cm}^{-1}$ was calculated from the slope of the linear regression (Supplemental Figure S8). 
1-aminoanthracene binding affinity to HSAF. A saturated solution of 1-AMA (Sigma Aldrich, technical grade) was prepared by sonication in Dulbecco's Phosphate Buffered Saline (DPBS, pH=7.4) and filtration with a $1.2 \mu \mathrm{m}$ glass microfiber filter (Whatman). Concentration was determined by UV/Vis spectroscopy utilizing an experimentally determined extinction coefficient of 1-AMA (Supplemental Figure S8). 1-AMA was added to a solution of HSAF (Sigma Aldrich, $0.2 \mu \mathrm{m}$ filtered, $5 \mu \mathrm{M}$ dimer) with final 1-AMA concentrations ranging from 1-250 $\mu \mathrm{M}$. After equilibration of 1AMA and HSAF, the samples were analyzed with fluorescence spectroscopy (Shimadzu RF-5301 PC spectrofluorometer) with an excitation wavelength of $380 \mathrm{~nm}$ and emission detection from 400$700 \mathrm{~nm}$. The curves were corrected by subtracting contributions from 1-AMA and HSAF alone. 1-AMA alone control values were determined mathematically from a linear regression of the fluorescence from 3 different samples of known concentration spanning the experimental range of 1-AMA concentrations (Supplemental Figure S9). The fluorescence was fitted to a sigmoidal dose-response curve (variable slope) using Prism 8 which yielded a $K_{D}$ of $9 \mu \mathrm{M}$ (95\% CI 8-11) (Supplemental Figure S9).

In-solution digestion of proteins. After photolabeling, the protein was precipitated with $200 \mu \mathrm{L}$ chilled acetone, pelleted (20 minutes, $\left.16,000 \times 9,4^{\circ} \mathrm{C}\right)$, gently washed with $300 \mu \mathrm{L}$ chilled 
acetone, and then air dried for 3-5 min. Pellets were redissolved in $93 \mu \mathrm{L}$ of $50 \mathrm{mM} \mathrm{NH} \mathrm{NCO}_{3}$ (sonicated if necessary) followed by addition of $1 \mu \mathrm{L}$ of $0.5 \mathrm{M}$ Dithiothreitol (DTT, Biorad, electrophysiology grade) and incubation at $56^{\circ} \mathrm{C}$ for $30 \mathrm{~min}$. After reduction with $\mathrm{DTT}, 2.7 \mu \mathrm{L}$ of $0.55 \mathrm{M}$ iodoacetamide (Sigma, $\geq 99 \%$ by NMR, crystalline) was added and the samples were incubated at room temperature in the dark for $45 \mathrm{~min}$. Then $2.5 \mu \mathrm{L}$ of $1 \mu \mathrm{g} / \mu \mathrm{L}$ sequencing grade modified trypsin (Promega) was added (ratio of 1:20 protease:protein) and the samples were incubated at $37^{\circ} \mathrm{C}$ for 16 hours. Samples were centrifuged for $10 \mathrm{~min}$ at $16,000 \mathrm{x} \mathrm{g}$, and $50 \mu \mathrm{L}$ of glacial acetic was added (Sigma) for a final $\mathrm{pH}<2$. Samples were incubated at room temperature for $5 \mathrm{~min}$ and then desalted using C18 stage tips prepared in house. ${ }^{1}$ C18 tips were made with 3M Empore C18 Solid Phase Extraction Disks. Eluent was dried with a vacuum centrifuge concentrator. Prior to MS analysis the peptide digestion was resuspended in $0.1 \%$ formic acid.

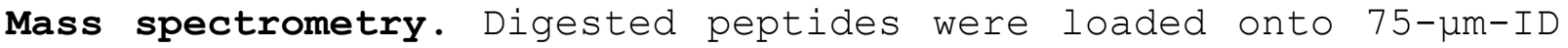
fused-silica capillary columns packed with a $20 \mathrm{~cm}$ long column of C18 reversed-phase resin (Reprosil-pur 120 c18, aq-3 um particles, Fisher Scientific), separated in an Easy-nanoLC 1000 system (Thermo Scientific) with a flow rate of $300 \mathrm{~nL} / \mathrm{min}$ and analyzed in an Orbitrap ${ }^{\mathrm{TM}}$ Fusion Tribrid Mass Spectrometer (Thermo Scientific). Peptides were eluted for $85 \mathrm{~min}$ in a linear gradient from $3 \div$ to 
15 in $10 \mathrm{~min}$, followed by $60 \mathrm{~min}$ to $50 \%$ and finally for $5 \mathrm{~min}$ at $98 \%$ Buffer B (80\% acetonitrile, $0.1 \%$ formic acid, v/v). Buffer A was $0.1 \%$ formic acid. The peptides were fragmented in higherenergy collisional dissociation (HCD) and data dependent acquisition mode was applied with a dynamic exclusion of $45 \mathrm{~s}$, in every 3 s cycle, one full MS scan was collected in with a scan range of 350 to $1200 \mathrm{~m} / \mathrm{z}$, a resolution of $60 \mathrm{~K}$ and a maximum injection time was $50 \mathrm{~ms}$ and automated gain control (AGC) of $4.0 \mathrm{e} 5$. Then MS2 scans were followed on the most intense parent ions. Ions were filtered with charge 2-5. An isolation window of $2 \mathrm{~m} / \mathrm{z}$ was used with quadruple isolation mode. Ions were fragmented using HCD with collision energy of $27 \%$. Orbitrap detection was used with normal scan range mode and rapid scan rate. ACG was set to be $5.0 e 4$ with a maximal injection time of $100 \mathrm{~ms}$.

Mass Spectrometry Analysis. Spectral analysis was conducted using MaxQuant 1.6.7.0 (Max Planck Institute of Biochemistry) ${ }^{2}$ using HSAF light chain sequence provided by UniProt database (UniProtKB: P02791). All analyses included dynamic oxidation of methionine $(+15.9949 \mathrm{~m} / \mathrm{z})$ and static alkylation of cysteine $(+57.0215 \mathrm{~m} / \mathrm{z}$; iodoacetamide alkylation). Adducts of AziFo (+218.0719 m/z) were included as a possible modification on any amino acid. Experiments were conducted in triplicate and samples containing no photoaffinity ligand were treated similarly to control for false 
positive detection of photoaffinity ligand modifications. Up to two missed cleavages were allowed in all searches. A mass variation tolerance of 10 ppm for MS and 0.8 Da for MS/MS were used. Trypsin was the specified digestion enzyme and a false discovery rate of $0.01 \div$ was applied.

SUPPLEMENTAL REFERENCES

Rappsilber, J.; Mann, M.; Ishihama, Y. Protocol for Micro-Purification, Enrichment, Pre-Fractionation and storage of Peptides for Proteomics Using StageTips. Nat. Protoc. 2007, 2 (8), $1896-1906$.

Tyanova, S.; Temu, T.; Cox, J. The MaxQuant Computational Platform for Mass Spectrometry-Based Shotgun Proteomics. Nat. Protoc. 2016, 11 (12), 2301-2319. 